\title{
IMPACTOS ESPERADOS DA HARMONIZAÇÃO INTERNACIONAL NO LUCRO DAS EMPRESAS BRASILEIRAS, NA PROXY DOS AJUSTES BRGAAP/USGAAP REPORTADOS PELAS EMISSORAS DE ADRS NA NYSE
}

\section{EXPECTED IMPACTS OF THE INTERNATIONAL HARMONIZATION ON BRAZILIAN ENTERPRISES' PROFIT: THE PROXY ADJUSTMENTS BRGAAP/USGAAP REPORTED BY ADRS ISSUERS ON NYSE}

\author{
EDILENE SANTANA SANTOS \\ Doutora em Controladoria e Contabilidade pela \\ Universidade de São Paulo \\ Professora da FGV - Escola de Administração de São \\ Paulo EAESP \\ São Paulo/SP, Brasil \\ E-mail: edilene.santos@fgv.br
}

\author{
JOANÍLIA NEIDE DE SALES E CIA \\ Doutora em Administração de Empresas pela \\ Fundação Getúlio Vargas/SP \\ Professora da Faculdade de Economia, Administração \\ e Contabilidade da Universidade de São Paulo \\ São Paulo/SP, Brasil \\ E-mail: joanilia@usp.br
}

\section{Resumo}

Este trabalho investiga o impacto esperado no lucro reportado pelas empresas a partir da harmonização internacional da contabilidade brasileira determinada pela Nova Lei das S/As (Lei 11.638/07). Tomam-se como proxy os ajustes BRGAAP/USGAAP aos resultados das emissoras brasileiras de ADRs na NYSE. Partindo do "Índice de Conservadorismo" de Gray (1980, 1988), que faz prever lucros menores (conservadorismo) apurados pelas normas brasileiras em relação às americanas, este trabalho investiga inconsistências encontradas em outro estudo, e discrimina o impacto das diferenças de normas em ajustes ao lucro, aplicando o "Índice de Comparabilidade Parcial” (Weetman et al., 1998) às empresas que publicaram no Formulário 20-F da SEC a Tabela de Reconciliação do Lucro entre 2001-2006. Confirmou-se o conservadorismo da contabilidade brasileira, com índice de 0,91 no subperíodo 2003-2006, prevendo-se, assim, que a harmonização internacional conduza a um aumento de 9,5\% nos lucros reportados pelas empresas brasileiras. Entre os ajustes com impactos mais relevantes, destacam-se: Correção Monetária, Ágio na Combinação de Negócios, Instrumentos Financeiros e Reavaliação de Ativos. O estudo pretende contribuir para incrementar o entendimento dos impactos futuros da harmonização ora iniciada e em fase de regulação.

Palavras-chave: Contabilidade Internacional; harmonização contábil; BRGAAp, USGAAP; índice de conservadorismo; índice de comparabilidade; Nova Lei das SAs.

\begin{abstract}
This study a estimates expected impacts on Brazilian companies' reported profits, arising from the international accounting harmonization, rendered mandatory by the Brazilian New Corporation Law (Law 11.638/07). BRGAAP/USGAAP profit adjustments reported by Brazilian issuers of ADRs on NYSE are taken as proxy. Gray's (1980, 1988) "Index of Conservatism" is applied, which enables to predict lower profits (conservatism) measured by Brazilian in relation to American accounting. Some inconsistencies observed in prior work, are examined. The "Partial Comparability Index" (Weetman et al., 1998) is applied to analyzing impacts of norms' differences on profit adjustments published in Profit Reconciliations of SEC Form 20-F from 2001 to 2006. Findings confirm the Brazilian accounting conservatism with an index of 0,91 for the subperiod 2003-2006, thus predicting that the international harmonization could lead to an average increase of $9,5 \%$ in reported profits by Brazilian companies. The most relevant adjustments - specifically Monetary Restatement 1996/97, Premium in Business Combinations, Financial Instruments and Assets Revaluation - were identified. The study intends to contribute to better understanding future impacts of the initiated harmonization and its regulation in Brazil.
\end{abstract}

Key words: International Accounting, accounting harmonization, BRGAAP, USGAAP, index of conservatism, comparability index, New Corporation Law.

Recebido em 03/08/2009 • Aceito em 20/08/2009 • $2^{\text {a }}$ versão aceita em 25/08/2009

Artigo originalmente apresentado no 20st Asian Pacific Conference on International Accounting Issues, Paris, 2008 


\section{INTRODUÇÃO}

A harmonização da contabilidade brasileira com o padrão internacional do IFRS (International Financial Reporting Standard), após anos de trâmites no Legislativo, foi finalmente determinada pela "Nova Lei das S/As" (Lei 11.638 de 28/12/2007). De fato, a harmonização tornou-se condição de competitividade no ambiente econômico global, no qual, cada vez mais, empresas brasileiras recorrem ao mercado internacional de capitais ou internacionalizam seus investimentos. A harmonização tornou-se ainda mais relevante para os investidores externos no Brasil, após a elevação do rating do país para investment grade em abril de 2008 pela Standard \& Poor's.

A transição inaugurada com a Nova Lei das S/As ressalta a relevância, para investidores, analistas e agentes do mercado global de capitais, de conhecer as diferenças existentes entre as normas nacionais e as internacionais. Além disso, uma investigação aplicada ao mercado há que focar as práticas contábeis das empresas, a fim de identificar de que forma e até que ponto as diferenças normativas têm produzido diferenças significativas nos lucros e demais informações reportadas. Por outro lado, no Brasil, a maioria dos estudos de contabilidade internacional se tem restringido à análise qualitativa das diferenças de normas (de jure); muito poucos, e de forma ainda exploratória, investigam o impacto quantitativo dessas diferenças nas práticas contábeis das empresas (diferenças de facto).

A Nova Lei das S/As determina que o IFRS seja adotado como padrão contábil das empresas abertas e de grande porte no Brasil, ensejando mudanças nas práticas do mercado, que até então vinha adotando predominantemente os USGAAP (United Stades Generaly Accepted Accounting Principles) como padrão internacional. Por isso, na ausência de séries históricas de demonstrações financeiras de empresas brasileiras conforme o IFRS, uma pesquisa do impacto das diferenças de normas no lucro das empresas há que se basear no padrão USGAAP, cujos dados estão disponíveis, pelo menos para o caso das empresas brasileiras com ADRs (American Depositary Receipts) na NYSE (New York Stock Exchange). Nesse sentido, este trabalho se insere na linha de estudos internacionais que analisam a diversidade contábil entre os países a partir da comparação com o padrão norteamericano.

Gray (1988), ao estudar as influências culturais nos sistemas contábeis dos diversos países, classificou o Brasil no grupo dos países latinos mais desenvolvidos, caracterizados pelo "conservadorismo", como tendência a apurar lucros inferiores aos mensurados pelos sistemas contábeis de influência anglo-americana, em particular dos Estados Unidos influência esta que também se exerce no padrão IFRS.

Essa característica conservadora das normas contábeis brasileiras em relação aos USGAAP foi em parte confirmada pelo estudo de Santos et al. (2007). Isso significaria, de um modo geral, que nas demonstrações financeiras das empresas brasileiras, a serem doravante gradativamente elaboradas conforme as normas internacionais, os lucros das empresas tenderão a ser maiores do que os reportados conforme a norma anterior.

Entretanto, ao contrário do observado num estudo de Gray (1980) para outros países, a pesquisa de Santos et al (2007) sobre as empresas brasileiras, revelou algumas inconsistências quanto ao conservadorismo dos resultados, quer ao longo do tempo, quer entre as empresas analisadas, deixando em aberto a explicação das razões de tal disparidade. A busca desse esclarecimento levou ao presente aprofundamento da investigação, mediante análise dos ajustes reportados na Tabela de Reconciliação do Lucro, que integra o Formulário 20-F da SEC (Security and Exchange Comission), pelas emissoras brasileiras de ADRs na NYSE. 
Uma vez que as normas brasileiras que originaram tais ajustes estão hoje (abril de 2008) em processo de regulação para adequação aos IFRS, a possibilidade de se estimar o impacto de cada ajuste entre os BRGAAP e os USGAAP no resultado das empresas poderá também contribuir para a identificação da sua relevância relativa na atual fase de transição para a harmonização no Brasil.

Assim, esta pesquisa aborda o seguinte problema: Qual o impacto esperado no lucro das empresas brasileiras com a harmonização contábil internacional, ensejada pela Nova Lei das S/As? Mais especificamente, a relevância das diferenças entre as normas contábeis, brasileira e americana, apontada na literatura, se reflete nas duplas demonstrações das emissoras de ADRs, em particular, nos ajustes ao resultado BRGAAP/USGAAP reportados no Formulário 20-F da SEC? Que ajustes mais ocorrem? Quais geram maior impacto no lucro? Como tais ajustes se comportam ao longo do tempo? Até que ponto esses ajustes esclarecem inconsistências entre empresas e no tempo, observadas em estudos anteriores?

Este trabalho tem como objetivo estimar o impacto esperado no lucro das empresas brasileiras a partir da harmonização da contabilidade com as normas internacionais, tendo como proxy as diferenças entre as práticas contábeis brasileira e americana, em particular os ajustes ao resultado reportados pelas emissoras brasileiras de ADRs na NYSE. Com isso, o presente estudo pretende contribuir para o melhor conhecimento científico preditivo dos efeitos da migração para o padrão contábil internacional, ora em curso.

Este estudo pode ser metodologicamente classificado como empírico-analítico, de caráter descritivo e comparativo, baseado em dados secundários.

Para estimar o impacto esperado da harmonização internacional no lucro das empresas brasileiras, este estudo toma como proxy os ajustes aos lucros apurados conforme as normas brasileiras e americanas. É de notar que as diferenças entre o IFRS e os USGAAP podem ser consideradas pequenas, tanto que a partir de 2007 a SEC passou a aceitar o padrão IFRS para empresas estrangeiras listadas em bolsas americanas, eliminando a necessidade de reconciliação das diferenças para os USGAAP. Assim, a série histórica disponível dos impactos das diferenças entre BRGAAP e USGAAP é tomada neste estudo como proxy dos impactos esperados das diferenças entre BRGAAP e IFRS a serem reportados com a harmonização internacional ora determinada e em fase de regulação.

\section{REVISÃO DA LITERATURA}

\subsection{CULTURA LOCAL E DIFERENÇAS DE NORMAS CONTÁBEIS (DE JURE) NACIONAIS}

A influência das diferentes tradições culturais, jurídicas e empresariais na contabilidade dos diversos países é investigada por vários estudiosos das diferenças entre normas no atual processo de harmonização contábil internacional. Dentre os trabalhos em geral sobre as diferenças entre as normas contábeis nacionais, bem como sobre suas razões ambientais e culturais, podem citar-se os de Gray $(1980,1985,1988)$, Doupnik \& Tsakumis (2004), Saudagaran (2001), Choi \& Meek (2005), Radebaugh et al. (2006) e outros.

Com foco no Brasil, as diferenças entre as normas (de jure) brasileiras, americanas e internacionais, são abordadas nos livros de Schmidt et al. (2004) e Perez (2005), bem como em notas técnicas de grandes empresas de auditoria, como a PricewaterhouseCooper (2004) e KPMG (2001). As influências do ambiente jurídico e educacional, cultural e do mercado são estudadas por Weffort (2003). Niyama (2005, p. 16s) sintetiza a tipologia dos modelos anglo-americano e da Europa Continental. 
Uma síntese dos fatores ambientais que determinam as características do sistema contábil de um país é apresentada por Saudagaran (2001, pp. 3-23):

- A natureza do mercado de capitais (mais voltado para o investidor ou para o credor, se é dotado ou não de instrumentos financeiros sofisticados, maior ou menor inserção no mercado global);

- Se há (por ex. USA, UK) ou não (por ex. Alemanha) dois sistemas para demonstrações financeiras e fiscais;

- Se há numerosas grandes empresas internacionalizadas;

- Se o sistema jurídico é legalista (code law, mais mandatório, formal e voltado para o usuário credor), predominante em países da Europa Continental e latinos em geral, ou consuetudinário (common law, construído a partir de contribuições por órgãos mais autônomos dos usuários, preventivo, mais voltado ao acionista), como nos países de colonização inglesa (id., p. 7);

- O nível de eficácia da fiscalização governamental da aplicação das regras existentes, para que as normas não sejam apenas "de jure", mas se incorporem nas práticas "de facto".

- O nível de inflação - se a contabilidade é feita por custos históricos ou em moeda constante (México, Bolívia);

- Vinculações políticas (ex-colônias, por ex) e econômicas (por ex. blocos como a NAFTA ou a ASEAN) entre países;

- O estatuto social e a influência da profissão contábil (maior nos países com leis consuetudinárias). Por exemplo, para cada 100.000 habitantes, a Nova Zelândia possui 500 auditores, a Inglaterra 352, os Estados Unidos 168, o Chile 87, 0 México 14 e o Brasil apenas 1 (id., p. 10).

- A existência de um sistema consistente de conceitos e objetivos da contabilidade no país;

- A qualidade da educação contábil.

É de notar, como observam Choi \& Meek (2005), que a harmonização, ao contrário da padronização, não visa a mera uniformização das normas contábeis, mas possibilita uma conveniente diferenciação nacional juntamente com a unificação internacional dos critérios das demonstrações:

"'Harmonization' is a process of increasing the compatibility of accounting practices by setting limits on how much they can vary. Harmonized standards are free of logical conflicts, and should improve the comparability of financial information from different countries. (...) People occasionally use the terms harmonization and standardization interchangeably, but in contrast to harmonization, standardization generally means the imposition of a rigid and narrow set of rules, and may even apply a single standard or rule to all situations. Standardization does not accommodate national differences (...) Harmonization is much more flexible and open; it does not take a one-size-fits-all approach, but accommodates some differences (...)". Choi \& Meek (2005, p. 275).

Nesse enfoque, o processo em curso no Brasil, após a Nova Lei das S/As pode ser caracterizado como harmonização e não padronização internacional. Como exemplos de algumas diferenciações, podem ser citadas a proibição pela Nova Lei das S/As da reavaliação de ativos, a qual é permitida pelos IFRS, bem como a obrigatoriedade da Demonstração do Valor Adicionado, prescrita pela mesma lei brasileira, mas não pelos IFRS. Uma comparação sintética das principais diferenças entre as normas contábeis brasileira e os US GAAP é apresentada na Tabela 1. 
Tabela 1 - Principais Diferenças entre as Normas Contábeis Brasileiras e os US GAAP

\begin{tabular}{|c|c|c|}
\hline Item & Normas Brasileiras (BRGAAP) & Normas Norte-Americanas (USGAAP) \\
\hline $\begin{array}{l}\text { Tratamento da } \\
\text { inflação }\end{array}$ & $\begin{array}{l}\text { Previa a contabilidade em moeda } \\
\text { constante, a qual foi extinta a partir } \\
\text { de } 1995 .\end{array}$ & $\begin{array}{l}\text { A correção monetária é exigida para países cuja } \\
\text { inflação acumulada for igual ou superior a } 100 \% \\
\text { nos últimos três anos. O Brasil ainda era } \\
\text { considerado uma economia inflacionária nesses } \\
\text { parâmetros em } 1996 \text { e } 1997 \text {. }\end{array}$ \\
\hline $\begin{array}{l}\text { Reavaliação de } \\
\text { Ativos }\end{array}$ & Permitida para Ativo Imobilizado & Não permitida \\
\hline $\begin{array}{l}\text { Leasing } \\
\text { Financeiro }\end{array}$ & $\begin{array}{l}\text { Arrendatário: Despesa } \\
\text { O bem é registrado no ativo apenas } \\
\text { no final do contrato. Parte da } \\
\text { prestação (contraprestação) é despesa } \\
\text { e parte é ativo realizável/diferido } \\
\text { (Valor Residual Garantido-VRG). } \\
\text { Arrendador: Ativo } \\
\text { O bem é ativo imobilizado. Parte da } \\
\text { prestação (contraprestação) é receita } \\
\text { e parte é obrigação (Valor Residual } \\
\text { Garantido). }\end{array}$ & $\begin{array}{l}\text { Arrendatário : Ativo e Passivo } \\
\text { São registrados o valor do bem (ou valor } \\
\text { presente das prestações, se menor) no Ativo e a } \\
\text { dívida relativa às parcelas a pagar no Passivo. } \\
\text { Parte da prestação (contraprestação) é despesa e } \\
\text { parte é redução do passivo em aberto (VRG) } \\
\underline{\text { Arrendador }: \text { Ativo = Contas a Receber. }}\end{array}$ \\
\hline $\begin{array}{l}\text { Capitalização de } \\
\text { Juros }\end{array}$ & $\begin{array}{l}\text { Obrigatória a capitalização de juros } \\
\text { apenas na fase pré-operacional. } \\
\text { A capitalização de juros devidos } \\
\text { durante a construção de ativos fora da } \\
\text { fase pré-operacional é facultativa. }\end{array}$ & $\begin{array}{l}\text { Capitalizam-se os juros devidos durante a } \\
\text { construção de ativo, incorporando-os ao } \\
\text { imobilizado. }\end{array}$ \\
\hline $\begin{array}{l}\text { Diferimento de } \\
\text { Despesas }\end{array}$ & $\begin{array}{l}\text { Gastos com pesquisa e } \\
\text { desenvolvimento e outros são } \\
\text { normalmente lançados como Ativo } \\
\text { Diferido e amortizados pelo prazo de } \\
5 \text { a } 10 \text { anos }\end{array}$ & $\begin{array}{l}\text { Gastos com pesquisa e desenvolvimento e } \\
\text { outros são considerados despesa do exercício } \\
\text { em que ocorrem, com uso restrito do } \\
\text { diferimento. }\end{array}$ \\
\hline $\begin{array}{l}\text { Combinação } \\
\text { empresas }\end{array}$ & $\begin{array}{l}\text { Reconhece como ágio a diferença } \\
\text { entre o valor pago na negociação e o } \\
\text { valor contábil dos ativos líquidos. } \\
\text { O ágio é amortizável em até } 10 \text { anos. }\end{array}$ & $\begin{array}{l}\text { Prevalece o método da compra, pelo qual ágio é } \\
\text { a diferença entre o valor pago na negociação e o } \\
\text { valor de mercado dos ativos líquidos. } \\
\text { O método da união de interesses (avaliação de } \\
\text { ativos ao contábil) é praticado somente em } \\
\text { certos casos. } \\
\text { O ágio ou goodwill não é amortizado, sendo } \\
\text { aplicado apenas o teste de impairment. }\end{array}$ \\
\hline $\begin{array}{l}\text { Títulos e Valores } \\
\text { Mobiliários }\end{array}$ & $\begin{array}{l}\text { Títulos de renda fixa: avaliados pelo } \\
\text { custo mais receita pro rata tempore } \\
\text { Títulos de renda variável: ganhos e } \\
\text { perdas são apurados apenas na } \\
\text { realização do investimento, sendo } \\
\text { efetuada uma provisão para perdas de } \\
\text { caráter permanente. } \\
\text { Para as instituições financeiras o } \\
\text { tratamento é similar aos USGAAP }\end{array}$ & $\begin{array}{l}\text { O tratamento contábil dos títulos depende de sua } \\
\text { classificação em três categorias: } \\
\text { 1) Títulos para negociação: avaliados a fair } \\
\text { value, com ganhos e perdas lançados no } \\
\text { resultado. } \\
\text { 2) Títulos mantidos até vencimento: avaliados } \\
\text { pelo custo mais receita pro rata tempore, } \\
\text { considerando a taxa de juros efetiva. } \\
\text { 3) Títulos disponíveis para venda (os não } \\
\text { classificados em nenhum dos outros dois } \\
\text { grupos): avaliados a fair value, com ganhos e } \\
\text { perdas lançados diretamente no patrimônio } \\
\text { líquido, numa conta de ajuste de avaliação } \\
\text { patrimonial. }\end{array}$ \\
\hline Derivativos & $\begin{array}{l}\text { Como regra geral, os derivativos são } \\
\text { contabilizados em contas de } \\
\text { compensação e devem ser } \\
\text { evidenciados em nota explicativa, } \\
\text { estimando-se seu valor de mercado. }\end{array}$ & $\begin{array}{l}\text { Todos os instrumentos financeiros derivativos } \\
\text { são registrados no balanço patrimonial, sendo } \\
\text { avaliados pelo seu fair value. }\end{array}$ \\
\hline
\end{tabular}




\section{Continuação}

\begin{tabular}{|c|c|c|}
\hline Stock options & $\begin{array}{l}\text { Basicamente as opções de compra de } \\
\text { ações são registradas quando a opção } \\
\text { é exercida. }\end{array}$ & $\begin{array}{l}\text { A contabilização é efetuada como se a opção } \\
\text { tivesse sido exercida. Se o preço de exercício for } \\
\text { menor que o de mercado, deve-se reconhecer a } \\
\text { perda de imediato. }\end{array}$ \\
\hline $\begin{array}{l}\text { Consolidação de } \\
\text { Demonstrações } \\
\text { Financeiras }\end{array}$ & $\begin{array}{l}\text { É efetuada a consolidação de todas as } \\
\text { subsidiárias/controladas, exceto as de } \\
\text { controle temporário. } \\
\text { Prevê a consolidação proporcional de } \\
\text { empresas controladas em conjunto } \\
\text { (joint ventures) }\end{array}$ & $\begin{array}{l}\text { É efetuada a consolidação apenas das } \\
\text { companhias abertas. } \\
\text { Joint ventures não são consolidadas, apenas } \\
\text { avaliadas por equivalência patrimonial }\end{array}$ \\
\hline Planos de pensão & $\begin{array}{l}\text { Requer o reconhecimento de ganhos } \\
\text { e perdas dados pela diferença entre os } \\
\text { ativos líquidos do plano e as } \\
\text { obrigações decorrentes dos benefícios } \\
\text { projetados apenas a partir de } \\
\text { dez/2001. Permitiu reconhecer os } \\
\text { ganhos e perdas apurados nessa } \\
\text { transição diretamente nos lucros } \\
\text { acumulados. }\end{array}$ & $\begin{array}{l}\text { Requer que os ganhos e perdas sejam lançados } \\
\text { no resultado. }\end{array}$ \\
\hline
\end{tabular}

\subsection{IMPACTO DAS DIFERENÇAS DE PRÁTICAS CONTÁBEIS (DE FACTO) NO LUCRO}

As abordagens comparativas entre sistemas contábeis vêm sendo estimuladas e facilitadas pelo crescente número de empresas estrangeiras com ADRs listadas em bolsas americanas, em especial na NYSE, as quais são obrigadas a apresentar anualmente à SEC (Security and Exchange Comission) suas demonstrações financeiras tanto no padrão contábil do seu país de origem quanto ajustadas para o padrão americano.

Como mencionado, em busca de um instrumento para analisar o impacto das normas contábeis dos diversos países na mensuração dos resultados das empresas, Gray (1980) propôs inicialmente o “Índice de Conservadorismo”, que relaciona os resultados apurados segundo práticas contábeis nacionais com um padrão internacional. Estudos posteriores de Weetman et al. (1998) renomearam esse índice para "Índice de Comparabilidade", tendo os USGAAP como base de comparação, uma vez que esses estudos não tinham como objetivo analisar o grau de conservadorismo da contabilidade dos respectivos países, mas apenas mensurar a magnitude do impacto das diferenças entre as normas contábeis desses países. 0 Índice de Comparabilidade, aplicado posteriormente em vários trabalhos internacionais, pode focar tanto a totalidade dos ajustes apresentados pelas empresas (Índice de comparabilidade Geral), ou ser aplicado a cada ajuste separadamente (Índice de Comparabilidade Parcial).

Neste estudo será mantida a terminologia original de "Índice de Conservadorismo" (IC) para o impacto total dos ajustes (ou seja, equivalente ao Índice de Comparabilidade Geral), empregando-se o termo "Índice de Comparabilidade Parcial” (ICP) para os impactos discriminados dos diversos ajustes. 
O Índice de Conservadorismo (IC), ou Índice de Comparabilidade Geral (ICG), é dado pela seguinte fórmula:

$$
I C=I C G=1-\left[\frac{\text { Lucro }_{U S A}-\text { Lucro }_{\text {Brazil }}}{\mid \text { Lucro }_{U S A} \mid}\right]
$$

Onde:

Lucro $_{\text {USA }}=$ lucros (ou retornos) ajustados para os USGAAP

LuCrO $_{B R A S I L}=$ lucros apurados conforme a prática local, no caso o Brasil

Assim, um Índice de Conservadorismo maior que 1 implicaria que o lucro apurado conforme as normas do país é maior (otimismo) que o lucro calculado segundo os US GAAP. Já um índice menor que 1 implicaria que o lucro apurado conforme as normas do país é menor (conservadorismo) do que o apurado conforme os US GAAP.

O Índice de Comparabilidade Parcial (ICP), que fornece uma medida relativa do impacto de cada ajuste ao lucro apurado segundo uma norma nacional para se obter o lucro em USGAAP, é calculado pela seguinte fórmula:

$$
I C P=1-\frac{\text { AjusteParcial }}{\mid \text { Lucro }_{U S A} \mid}
$$

Como observam Weetman et al. (1998), o Índice de Comparabilidade (IC), tende a resultados extremos quando o denominador tende a zero, limitação esta compensada pela utilidade do Índice e pelo fato de tal ocorrência não ser freqüente nas amostras estudadas. Essa característica do IC enseja, neste estudo, atenção a outliers.

Vários trabalhos aplicam a metodologia de Gray na análise comparativa de sistemas contábeis nacionais, como entre Inglaterra, França e Alemanha (Gray, 1980); entre Inglaterra e Estados Unidos (Weetman \& Gray, 1990); entre Estados Unidos e Japão (Cooke, 1993); entre Estados Unidos, Inglaterra, Suécia e Holanda (Weetman \& Gray, 1991); e outros.

Embora o Brasil seja o terceiro país em número de empresas com ADRs na NYSE (em 31/12/2006 eram 32 empresas), depois apenas do Canadá (com 86 empresas) e da Inglaterra (com 45 empresas), há, como mencionado, poucos estudos comparativos que incluem a abordagem de facto, estudando os impactos das diferenças normativas entre sistemas contábeis nacionais nas demonstrações financeiras das empresas brasileiras.

Dentre esses, Lemes et al. (2007) e Carvalho et al. (2007) investigaram a comparabilidade das demonstrações contábeis elaboradas conforme as normas brasileira e americana de empresas brasileiras emissoras de ADRs na NYSE no ano de 2005.

Outros estudos enfocam o conservadorismo da contabilidade brasileira em relação aos USGAAP mediante outros modelos que não os de Gray, como a dissertação de Santos (2006), que investiga o reconhecimento assimétrico de boas e más notícias e o gerenciamento de resultados no retorno econômico de emissoras de ADRs. (Ver também Costa, 2004).

Santos et al. (2007), utilizando os índices de Gray (1980) e de Weetman et al. (1998), mensuraram os impactos das diferenças entre os sistemas contábeis brasileiro e americano nos lucro das emissoras de ADRs na NYSE no período 2001 a 2005.

Algumas questões surgem a partir do estudo de Santos et al. (2007). Foi obtido um IC médio para o período 2001-2005 de 0,83, ou seja, o lucro apurado conforme as normas brasileiras mostrou-se em média $17 \%$ inferior ao lucro obtido pelos padrões americanos, indicando uma tendência ao conservadorismo contábil, conforme previsto por Gray (1988). No entanto, os autores notam que, dada a grande dispersão nos números entre as empresas 
e setores ao longo do período total, essa média não pôde ser considerada estatisticamente significativa ao nível de $10 \%$. Este nível de significância só foi obtido no subperíodo de 2003-2005. Nesse ponto, poder-se-ia perguntar se a baixa significância estatística dos resultados não estaria relacionada ao fato de o referido estudo ter empregado o teste $t$ para análise dos dados, assumindo a normalidade da distribuição da população, com base no teorema do limite central (para amostras de 30 ou mais observações, a distribuição da população se aproxima de uma normal). Assim, o presente estudo, aprofundando a investigação de Santos et al. (2007), examina essa normalidade e aplica um teste nãoparamétrico.

Por outro lado, essa dispersão denota, ainda, uma considerável inconsistência de valores entre as práticas contábeis das empresas brasileiras, ao contrário das pesquisas realizadas com as empresas de outros países (Gray, 1980; Weetman \& Gray, 1990 e 1991; Norton, 1995; e outros). Essa inconsistência ressalta da Tabela 2, que compara a distribuição de frequência do Índice de Conservadorismo da França, Alemanha e Inglaterra, conforme investigado por Gray (1980, p.68) com a distribuição do IC do Brasil, conforme Santos et al. (2007, p.13). Assim, a França e Alemanha, teoricamente conservadoras na mensuração do lucro em relação aos USGAAP, de fato apresentam concentrações em ICs menores que 0,95 (respectivamente de $77 \%$ e $75 \%$ ), com pequena ocorrência no pólo oposto (respectivamente 15\% e 17\%); a Inglaterra, teoricamente otimista, concentra $58 \%$ dos dados em ICs maiores que 1,05, e apenas $15 \%$ no pólo oposto. Já no Brasil que, teoricamente, deveria ser caracteristicamente conservador, o mencionado estudo de Santos et al. (2007), embora revele uma ênfase conservadora, mostra um comportamento pouco consistente no período analisado (2001 a 2005), com concentração de dados nos dois pólos opostos: $47,5 \%$ no polo conservador e $37,4 \%$ no polo otimista.

Tabela 2: Comparação da Distribuição de Frequiência dos ICs: França, Alemanha, Inglaterra e Brasil

\begin{tabular}{|c|c|c|c|c|c|c|c|c|c|}
\hline \multirow{2}{*}{\multicolumn{2}{|c|}{ Índice de Conservadorismo }} & \multicolumn{2}{|c|}{ França } & \multicolumn{2}{|c|}{ Alemanha } & \multicolumn{2}{|c|}{ Inglaterra } & \multicolumn{2}{|c|}{ Brasil } \\
\hline & & $\mathbf{N}^{\mathbf{o}}$ & $\%$ & $\mathbf{N}^{\mathbf{o}}$ & $\%$ & $\mathbf{N}^{\mathbf{0}}$ & $\%$ & $\mathbf{N}^{\mathbf{0}}$ & $\%$ \\
\hline I. & $<0,50$ & 12 & $20 \%$ & 12 & $11 \%$ & 2 & $2 \%$ & 18 & $13 \%$ \\
\hline II. & $0,50-0,74$ & 20 & $33 \%$ & 35 & $31 \%$ & 10 & $9 \%$ & 11 & $8 \%$ \\
\hline III. & $0,75-0,94$ & 14 & $23 \%$ & 37 & $33 \%$ & 5 & $4 \%$ & 37 & $27 \%$ \\
\hline Pessin & & 46 & $77 \%$ & 84 & $75 \%$ & 17 & $15 \%$ & 66 & $47,5 \%$ \\
\hline IV. & $0,95-0,99$ & 4 & $7 \%$ & 4 & $4 \%$ & 11 & $9 \%$ & 12 & $9 \%$ \\
\hline V. & 1 & 1 & $2 \%$ & 1 & $1 \%$ & 4 & $3 \%$ & 0 & \\
\hline VI. & $1,01-1,05$ & 0 & $0 \%$ & 4 & $4 \%$ & 17 & $15 \%$ & 9 & $6 \%$ \\
\hline Neutr & & 5 & $8 \%$ & 9 & $8 \%$ & 32 & $28 \%$ & 21 & $15,1 \%$ \\
\hline VII. & $1,06-1,25$ & 3 & $5 \%$ & 6 & $5 \%$ & 37 & $32 \%$ & 24 & $17 \%$ \\
\hline VIII. & $1,26-1,5$ & 2 & $3 \%$ & 6 & $5 \%$ & 20 & $17 \%$ & 13 & $9 \%$ \\
\hline IX. & $>1,5$ & 4 & $7 \%$ & 7 & $6 \%$ & 10 & $9 \%$ & 15 & $29 \%$ \\
\hline Otimi & & 9 & $15 \%$ & 19 & $17 \%$ & 67 & $58 \%$ & 52 & $37,4 \%$ \\
\hline Total & & 60 & $100 \%$ & 112 & $100 \%$ & 116 & $100 \%$ & 139 & $100 \%$ \\
\hline
\end{tabular}

Fonte: Adaptado de Gray (1980, p. 68) e Santos et al. (2007, p. 13).

No referido estudo de Santos et al. (2007), também foi considerado peculiar o comportamento da mediana do IC, que foi maior que 1 nos dois primeiros anos $(1,07 \mathrm{em}$ 2001 e 1,22 em 2002) e menor que 1 nos três últimos anos (0,79 em 2003, 0,94 em 2004 e $0,93 \mathrm{em} \mathrm{2005).} \mathrm{Esse} \mathrm{comportamento} \mathrm{inconsistente} \mathrm{do} \mathrm{IC} \mathrm{no} \mathrm{tempo} \mathrm{aponta} \mathrm{para} \mathrm{o} \mathrm{exame}$ das causas, em particular, dos ajustes ao resultado que poderiam ter provocado tais diferenças.

0 presente trabalho pretende contribuir para o aprofundamento do estudo de Santos et al. (2007) e esclarecimento das razões de tais inconsistências. 


\section{METODOLOGIA}

Para a elaboração deste estudo, tomou-se o conjunto das empresas brasileiras com ADRs na NYSE com dados disponíveis no período de 2001 a 2006, totalizando 30 empresas. Os dados foram obtidos a partir dos Formulários 20-F publicados no site da NYSE (http://www.nyse.com/), preenchidos anualmente pelas empresas brasileiras emissoras de ADRs. Uma vez que oss dados podem estar expressos no Formulário 20-F em R\$ ou em US\$, as chamadas moedas de relatório, os valores de lucro reportados em US\$ foram convertidos para R\$ pela taxa de câmbio média de cada ano ${ }^{1}$.

Diante das mencionadas inconsistências apontadas no estudo de Santos et al. (2007), verificou-se que na série histórica utilizada no referido estudo foram tomados os dados originais dos Formulários $20-\mathrm{F}$ de cada ano. No entanto, constatou-se que nos relatórios publicados separadamente na NYSE em anos posteriores, que incluem para fins de comparação os dados dos dois últimos anos, ocorreram alterações e correções freqüentes e expressivas. Assim, optou-se por incluir essas alterações e correções no presente trabalho. Dessa forma, ao invés da coleta a partir dos Formulários 20-F de cada ano, neste trabalho os dados de 2006, 2005 e 2004 foram coletados do Formulário 20-F de 2006, publicado em 2007; os dados de 2003 foram coletados do formulário publicado em 2006; os de 2002, do formulário publicado em 2005; e os de 2001, do formulário publicado em 2004.

A incorporação dessas alterações e correções de anos anteriores efetuadas pelas empresas, contribuiu para superar discrepâncias ou inconsistências mencionadas por Santos et al. (2007). De fato, conforme indicado na Tabela 3 (dados com fundo em cinza), a maioria das empresas efetuou alterações ou correções: dentre as 30 emissoras de ADRs na NYSE, apenas oito mantiveram inalterados todos os números de exercícios anteriores.

Das 30 empresas com ADRs na NYSE que disponibilizaram o relatório 20-F no período de 2001 a 2006, apenas 15 (50\%) apresentaram a Tabela de Reconciliação do Lucro, que mostra o detalhamento das várias categorias de ajustes efetuados ao lucro apurado conforme regras brasileiras para se obter o lucro ajustado para os USGAAP. Assim, embora este estudo apresente os ICs das 30 empresas, para o cálculo dos ICPs foram usados apenas os dados publicamente disponíveis, ou seja, os dados das 15 empresas brasileiras com ADRs na NYSE que publicaram a planilha de reconciliação dos lucros no período de 2001 a 2006.

Foi aplicado nas diversas amostras o teste de D’Agostino-Pearson, que não confirmou a normalidade da distribuição populacional. Assim, para a análise dos resultados, além dos instrumentos de estatística descritiva, foi utilizado o teste não paramétrico de sinais por postos de Wilcoxon. Com isso, a presente investigação prioriza a mediana como medida central. Assim, com o objetivo de estimar os resultados esperados com a adoção do IFRS no Brasil, tomando como proxy os ajustes ao resultado BRGAAP/USGAAP, e visando esclarecer as mencionadas discrepâncias apontadas no referido estudo de Santos et al. (2007), o presente trabalho examinará as seguintes hipóteses:

$\mathrm{H}_{0}$ : $\mathrm{O}$ IC é igual a 1 (um) em todo o período

$\mathrm{H}_{1}$ : O IC é maior que 1 (um) no subperíodo 2001-2002

$\mathrm{H}_{2}$ : O IC é menor que 1 (um) no subperíodo 2003-2006

\footnotetext{
${ }^{1}$ Foram utilizadas as seguintes taxas câmbio médias: $2006=2,177 ; 2005=2,434 ; 2004=2,926 ; 2003=3,072$; $2002=2,931 ; 2001=2,352$.
} 


\section{RESULTADOS DA PESQUISA}

\subsection{RESULTADOS PARA 30 EMISSORAS DE ADRS NA NYSE}

A Tabela 3 apresenta no Painel A os ICs anuais das 30 empresas brasileiras com ADRs na NYSE, bem como a média e mediana por empresa no período 2001-2006. As células em branco correspondem a valores não disponíveis. Os dados em negrito representam as 15 empresas que publicaram a Tabela de Reconciliação do Lucro no Formulário 20-F, cujos ICPs são analisados posteriormente neste trabalho.

Tabela 3 - ICs de 2001-2006: Estatísticas

Base Dados: Últimas Publicações

\begin{tabular}{|c|c|c|c|c|c|c|c|c|}
\hline \multirow{2}{*}{ Painel A: ICs das Empresas } & \multicolumn{2}{|c|}{ 2001-2006 } & \multicolumn{6}{|c|}{ IC $=1-($ USGAAP-BRGAAP $) / \mid$ USGAAP $\mid$} \\
\hline & Mediana & Média & 2006 & 2005 & 2004 & 2003 & 2002 & 2001 \\
\hline Ambev - Companhia de Bebidas das Americas & 0,789 & $\mathbf{0 , 7 8 9}$ & $\mathbf{0 , 6 8 5}$ & $\mathbf{0 , 5 7 0}$ & $\mathbf{0 , 7 8 9}$ & $\mathbf{0 , 8 3 6}$ & $\mathbf{0 , 9 2 0}$ & 0,934 \\
\hline Aracruz Celulose S.A. & 1,607 & 1,946 & 1,160 & 1,400 & 1,607 & 1,913 & 0,037 & 5,558 \\
\hline Banco Bradesco, S.A. & 0,920 & 0,913 & 0,782 & 0,874 & 0,920 & 1,002 & 0,944 & 0,956 \\
\hline Banco Itau Holding Financeira S.A & 0,934 & 0,934 & 0,731 & 0,963 & 0,815 & 0,961 & 0,840 & 1,296 \\
\hline Brasil Telecom Participações S.A. & $\mathbf{0 , 1 7 0}$ & $-0,044$ & $\mathbf{0 , 6 2 9}$ & $-1,799$ & $\mathbf{0 , 3 4 7}$ & $\mathbf{0 , 1 7 0}$ & $-0,036$ & 0,426 \\
\hline Braskem S.A. & 0,795 & $\mathbf{0 , 7 9 1}$ & $\mathbf{0 , 6 2 7}$ & 0,844 & $\mathbf{0 , 8 1 5}$ & $\mathbf{0 , 5 6 9}$ & $\mathbf{0 , 7 9 5}$ & 1,099 \\
\hline Companhia Brasileira de Distribuição & 0,964 & 1,992 & 5,899 & $\mathbf{0 , 9 5 0}$ & $\mathbf{0 , 7 5 6}$ & $\mathbf{0 , 7 6 9}$ & 2,614 & 0,964 \\
\hline Companhia Energética de Minas Gerais - CEMIG & 0,858 & $-12,269$ & 2,448 & 1,107 & 0,796 & 0,858 & $-81,486$ & 2,665 \\
\hline Companhia Paranaense de Energia (COPEL) & 1,417 & 2,051 & $\mathbf{1 , 2 1 9}$ & $\mathbf{0 , 9 0 3}$ & 2,979 & 4,494 & 1,294 & 1,417 \\
\hline Companhia Siderúrgica Nacional & 0,830 & 0,830 & 0,716 & 0,913 & 0,892 & 0,629 & 1,590 & 0,242 \\
\hline Companhia Vale do Rio Doce & 0,945 & 0,945 & 0,945 & 0,886 & 0,858 & 0,948 & 1,025 & 1,008 \\
\hline CPFL Energia S.A. & 0,765 & $\mathbf{0 , 4 3 5}$ & 1,121 & $\mathbf{0 , 9 2 0}$ & 0,749 & $-1,395$ & $\mathbf{0 , 7 8 2}$ & \\
\hline Embraer-Empresa Brasileira de Aeronautica & 1,192 & 1,192 & 0,732 & 0,653 & 1,129 & 1,406 & 1,807 & 1,425 \\
\hline Embratel Participações S.A. & $\mathbf{0 , 8 0 2}$ & 0,796 & & $\mathbf{0 , 3 3 9}$ & 1,120 & $\mathbf{0 , 6 3 8}$ & 1,076 & $\mathbf{0 , 8 0 7}$ \\
\hline Gerdau S.A. & 0,969 & 0,969 & 0,874 & 1,022 & 0,835 & 0,726 & 1,176 & 1,179 \\
\hline Gol Linhas Aéreas Inteligentes S.A. & 0,827 & 0,835 & 1,203 & 0,827 & 0,664 & 0,644 & & \\
\hline Perdigão S.A. & 1,026 & 1,550 & $\mathbf{0 , 8 2 7}$ & 1,013 & 1,012 & 1,259 & 4,166 & 1,026 \\
\hline Petróleo Brasileiro S.A. - Petrobras & 0,986 & 1,023 & 0,928 & 0,942 & 0,986 & 0,883 & 1,196 & 1,202 \\
\hline SABESP & 1,251 & 3,179 & 1,251 & 1,094 & 1,229 & 1,297 & 1,233 & 12,969 \\
\hline Sadia S.A. & 1,001 & 0,958 & 1,044 & 1,090 & 0,896 & 1,001 & 1,001 & 0,713 \\
\hline TAM S.A. & 0,546 & 0,546 & $\mathbf{0 , 6 8 7}$ & $\mathbf{0 , 4 3 9}$ & $\mathbf{0 , 7 9 3}$ & $\mathbf{0 , 2 6 6}$ & & \\
\hline Tele Norte Celular Participações S.A. & 1,129 & 0,997 & 1,129 & $-0,113$ & 1,969 & 0,106 & 1,449 & 1,441 \\
\hline Tele Norte Leste Participacoes S.A. & $\mathbf{1 , 2 5 3}$ & 1,471 & 1,091 & 1,253 & 1,007 & $\mathbf{0 , 2 1 8}$ & 1,702 & 3,559 \\
\hline Telecomunicaçôes de Sao Paulo S/A-Telesp & $\mathbf{0 , 9 7 2}$ & 1,046 & $\mathbf{0 , 9 6 1}$ & 0,964 & 0,999 & $\mathbf{0 , 7 9 0}$ & 1,593 & $\mathbf{0 , 9 7 2}$ \\
\hline Telemig Celular Participações S.A. & 1,060 & 1,299 & 0,881 & 1,083 & 1,060 & 0,687 & 3,051 & 1,032 \\
\hline Tim Participações S.A. & $\mathbf{0 , 9 5 9}$ & $\mathbf{0 , 9 5 4}$ & 0,615 & 0,959 & $\mathbf{1 , 0 1 2}$ & $\mathbf{0 , 8 7 2}$ & $\mathbf{1 , 0 2 0}$ & 1,245 \\
\hline Ultrapar Participacoes S.A. & $\mathbf{1 , 0 3 6}$ & 1,086 & 1,006 & $\mathbf{1 , 0 3 6}$ & 1,003 & $\mathbf{0 , 8 5 5}$ & 1,545 & 1,075 \\
\hline União de Bancos Brasileiros S.A (Unibanco) & 1,998 & 1,829 & 1,639 & 1,998 & 1,096 & 2,113 & 2,123 & 2,004 \\
\hline Vivo Participações S.A. & 1,075 & 0,249 & 2,035 & 0,447 & 1,184 & $-4,483$ & 1,237 & $\mathbf{1 , 0 7 5}$ \\
\hline Votorantim Celulose e Papel S.A. & 0,891 & 0,987 & 0,810 & 0,855 & 0,891 & 1,138 & 1,399 & 0,832 \\
\hline \multirow{2}{*}{ Painel B: Estatísticas por Ano } & \multicolumn{6}{|c|}{ Amostra Completa } & \multicolumn{2}{|c|}{ Sem Outliers } \\
\hline & 2006 & 2005 & 2004 & 2003 & 2002 & 2001 & 2002 & 2001 \\
\hline Mediana & 0,945 & 0,931 & 0,953 & 0,845 & 1,214 & 1,075 & 1,233 & 1,075 \\
\hline Média & 1,196 & 0,814 & 1,040 & 0,739 & $-1,568$ & 1,819 & 1,392 & 1,390 \\
\hline Desvio-padrão & 0,994 & 0,610 & 0,464 & 1,339 & 15,685 & 2,466 & 0,852 & 1,077 \\
\hline Mínimo & 0,615 & $-1,799$ & 0,347 & $-4,483$ & $-81,486$ & 0,242 & $-0,036$ & 0,242 \\
\hline Máximo & 5,899 & 1,998 & 2,979 & 4,494 & 4,166 & 12,969 & 4,166 & 5,558 \\
\hline Estatística z (teste de Wilcoxon) & $-0,465$ & $-2,139$ & $-1,018$ & $-1,594$ & 2,414 & 2,054 & 2,547 & 1,829 \\
\hline$p$-value & $32,1 \%$ & $1,6 \%$ & $15,4 \%$ & $5,5 \%$ & $0,8 \%$ & $2,0 \%$ & $0,5 \%$ & $3,4 \%$ \\
\hline $\mathrm{N}^{\circ}$ de Observações & 29 & 30 & 30 & 30 & 28 & 27 & 27 & 26 \\
\hline \multirow[b]{2}{*}{$\begin{array}{l}\text { Painel C: Estatísticas por Período } \\
\text { de Abrangência }\end{array}$} & \multicolumn{5}{|c|}{ Amostra Completa } & \multicolumn{3}{|c|}{ Sem Outliers } \\
\hline & $\begin{array}{c}6 \text { anos } \\
2001 \text { a } \\
2006\end{array}$ & $\begin{array}{l}4 \text { anos } \\
2003 \text { a } \\
2006\end{array}$ & $\begin{array}{l}2 \text { anos } \\
2001 \text { a } \\
2002\end{array}$ & $\begin{array}{c}5 \text { anos } \\
2001 \text { a } \\
2005\end{array}$ & $\begin{array}{l}3 \text { anos } \\
2003 \text { a } \\
2005\end{array}$ & $\begin{array}{c}6 \text { anos } \\
2001 \text { a } \\
2006\end{array}$ & $\begin{array}{l}5 \text { anos } \\
2001 \text { a } \\
2005\end{array}$ & $\begin{array}{l}\text { anos } \\
2001 \text { a } \\
2002\end{array}$ \\
\hline Mediana & 0,964 & 0,913 & 1,176 & 0,972 & 0,900 & 0,964 & 0,972 & 1,176 \\
\hline Média & 0,676 & 0,945 & 0,095 & 0,573 & 0,865 & 1,083 & 1,060 & 1,391 \\
\hline Desvio-padrão & 6,400 & 0,923 & 11,351 & 6,996 & 0,890 & 0,954 & 0,948 & 0,959 \\
\hline Mínimo & $-81,486$ & $-4,483$ & $-81,486$ & $-81,486$ & $-4,483$ & $-4,483$ & $-4,483$ & $-0,036$ \\
\hline Máximo & 12,969 & 5,899 & 12,969 & 12,969 & 4,494 & 5,899 & 5,558 & 5,558 \\
\hline Estatística z (teste de Wilcoxon) & $-0,288$ & $-2,776$ & 2,949 & $-0,189$ & $-2,990$ & $-0,292$ & $-0,192$ & 3,121 \\
\hline$p$-value & $38,7 \%$ & $0,3 \%$ & $0,2 \%$ & $42,5 \%$ & $0,1 \%$ & $38,5 \%$ & $42,4 \%$ & $0,1 \%$ \\
\hline $\mathrm{N}^{\circ}$ de Observações & 174 & 119 & 55 & 145 & 90 & 172 & 143 & 53 \\
\hline
\end{tabular}


No painel B são apresentadas as estatísticas gerais por ano, tanto considerando a amostra completa quanto após a eliminação de dois outliers ${ }^{2}$. 0 fato de as medianas dos ICs serem maiores que 1 em 2001 e 2002, tornando-se, entretanto, menores que 1 a partir de 2003, indicaria, de modo intrigante, tal como em Santos et al. (2007), e contrariamente à teoria, que a contabilidade brasileira seria otimista em 2001 e 2002, passando a ser conservadora a partir de 2003. Essa assimetria temporal se confirma, de um modo geral, a partir da aplicação do teste não-paramétrico de Wilcoxon, que apresenta $p$-values aceitáveis, rejeitando $\mathrm{H}_{0}$ em todos os anos, exceto em 2004 e 2006.

Para aprofundar o exame dessa inconsistência na série temporal estudada, buscouse examinar o comportamento dos ICs mediante agrupamentoes dos anos em dois subperíodos, 2001-2002 e 2003-2006, conforme o Painel C. O teste de Wilcoxon indica que não há um comportamento consistente para todo o período estudado ( $p$-value $=38,7 \%$ ). Por outro lado, ficou confirmada a assimetria entre os dois subperíodos ( $p$-values $=0,1 \%$ e $0,3 \%$ ), com a mediana do IC de 1,18 no primeiro subperíodo e de 0,91 no segundo, ambos estatisticamente significativos a $1 \%$.

Isso corrobora, pelo menos nos quatro anos mais recentes, o conservadorismo dos resultados apurados conforme a contabilidade brasileira em relação aos USGAAP, como previsto na teoria. Como inferência, considerando-se os resultados em USGAAP como proxy dos IFRS, pode-se esperar que a harmonização contábil internacional fará os lucros reportados pelas empresas brasileiras tender a um novo patamar, aproximadamente 9,5\% maior $(1 / 0,913)$ que os apurados atualmente.

Para melhor comparação entre os resultados deste estudo e os do período estudado por Santos et al. (2007), apresentados na Tabela 4, a Tabela 3 inclui as colunas dos períodos 2003-2005 e 2001-2005. Pode ser verificado que em todos os anos estudados, bem como nos dois subperíodos, as médias se alteraram e o $p$-value diminuiu expressivamente. Assim, os resultados deste estudo esclarecem as inconsistências identificadas no estudo de Santos et al (2007), que havia encontrado resultados estatisticamente significativos a $10 \%$ apenas no subperíodo 2003-2005. Isso indica que a consideração das correções das demonstrações efetuadas pelas empresas nas publicações de exercícios posteriores, somada à utilização de teste não-paramétrico, representa uma contribuição metodológica da presente investigação.

Tabela 4: Estatísticas dos ICs de 2001 a 2005 conforme Santos et al. (2007) Base de Dados: Publicações Originais

\begin{tabular}{|l|r|r|r|r|r|r|r|r}
\hline \multirow{2}{*}{ Métricas } & \multicolumn{6}{|c|}{ Resultados por ano } & \multicolumn{3}{c}{ Resultados Agrupados } \\
\cline { 2 - 8 } \multicolumn{1}{c|}{} & $\mathbf{2 0 0 5}$ & $\mathbf{2 0 0 4}$ & $\mathbf{2 0 0 3}$ & $\mathbf{2 0 0 2}$ & $\mathbf{2 0 0 1}$ & $\mathbf{2 0 0 1}$ a 2005 & $\mathbf{2 0 0 1}$ a 2002 & $\mathbf{2 0 0 3}$ a 2005 \\
\hline Mediana & 0,931 & 0,943 & 0,790 & 1,216 & 1,072 & 0,961 & 1,107 & 0,891 \\
Média & 0,841 & 0,995 & 0,680 & $(0,157)$ & 1,799 & 0,833 & 0,821 & 0,841 \\
Desvio-padrão & 0,599 & 0,507 & 1,340 & 7,650 & 2,470 & 3,545 & 5,714 & 0,895 \\
Estatística t & $-1,400$ & $-0,050$ & $-1,287$ & $-0,771$ & 1,649 & $-0,554$ & $-0,226$ & $-1,660$ \\
p-value & $17,3 \%$ & $96,0 \%$ & $20,9 \%$ & $44,8 \%$ & $11,2 \%$ & $58,0 \%$ & $82,2 \%$ & $10,0 \%$ \\
$\mathrm{~N}^{\mathbf{o}}$ de Observações & 28 & 30 & 29 & 26 & 26 & 139 & 52 & 87 \\
\hline
\end{tabular}

Fonte: Elaborado a partir de Santos et al. (2007, p.102).

\footnotetext{
${ }^{2}$ Os valores de ICs $\geq 12$ e ICs $\leq-11$, ou seja, valores 12 vezes maiores ou menores que 1 , foram considerados extremos, e como tais, excluídos. Assim, foi eliminado um outlier com IC = 12,969 em 2001 e outro com IC = - 81,426 em 2002. É de notar que os próximos números extremos, estes não eliminados, estão na ordem de 5 (5,899 em 2006; 5,558 em 2001 e -4,483 em 2003).
} 


\subsection{EMPRESAS QUE APRESENTARAM PLANILHAS DE AJUSTES $X$ TOTAL DE EMISSORAS DE ADRS}

Tabela 5 - Comparação dos Resultados: Empresas que Apresentaram Planilha de Ajustes versus Total de Emissoras de ADRs na NYSE

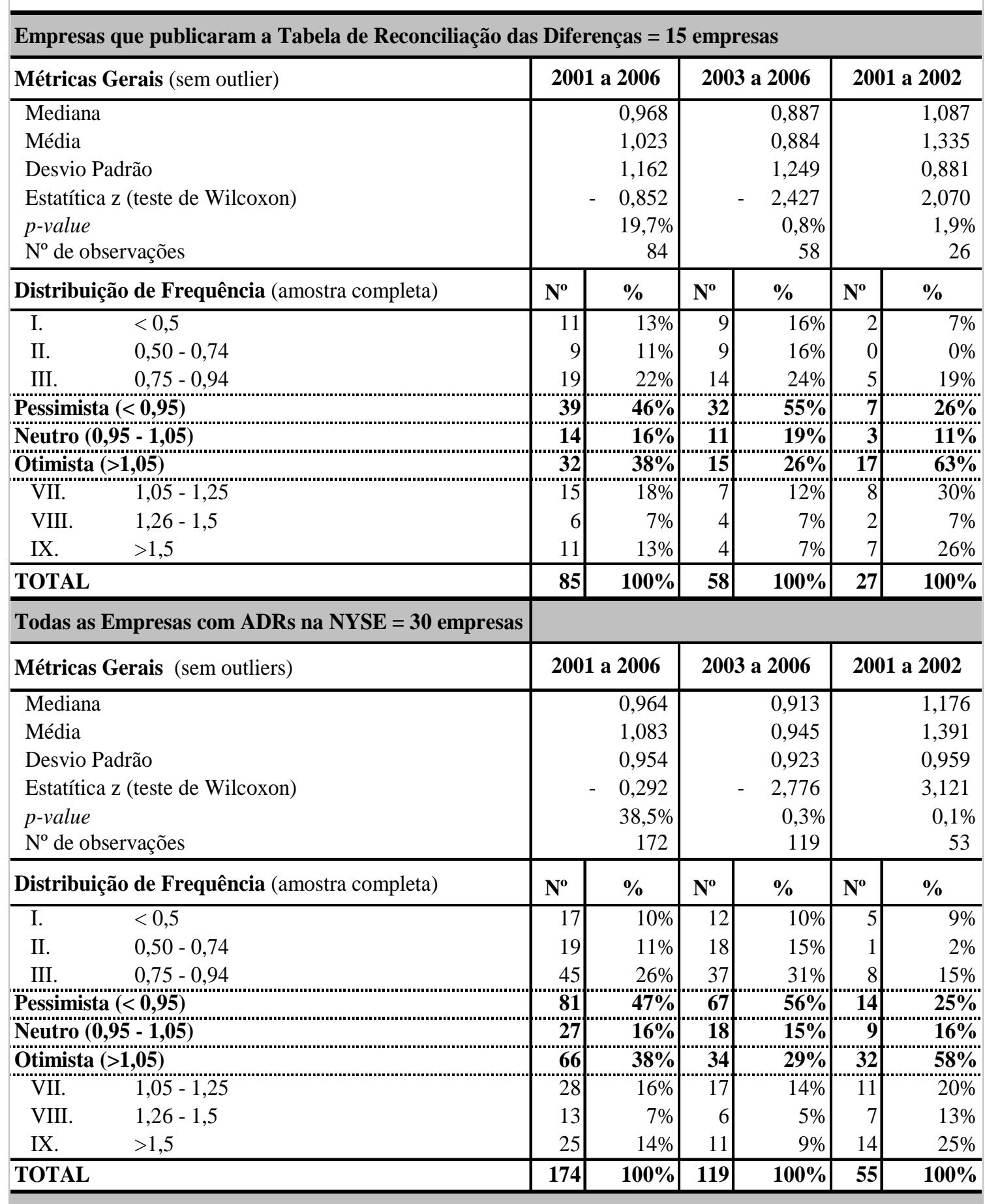

A Tabela 5 compara os indicadores gerais e a distribuição de freqüência das 30 empresas brasileiras emissoras de ADRs na NYSE com as 15 empresas que publicaram a Tabela de Reconciliação de Lucros no Formulário 20-F no período. A relativa simetria 
desses valores entre ambas as populações, quer para o período total 2001-2006 quer para os subperíodos 2003-2006 e 2001-2002, faz inferir que as 15 empresas analisadas no trabalho constituem amostra representativa do total das emissoras brasileiras de ADRs na NYSE no período e, que, portanto, os resultados relativos às 15 empresas estudadas poderiam ser extrapolados para a população das 30 emissoras de ADRs na NYSE.

\subsection{VISÃO GERAL DOS AJUSTES - ANÁLISE DOS ÍNDICES DE COMPARABILIDADE PARCIAL (ICP)}

Tabela 6 - Ocorrência, Média e Mediana dos Índices de Comparabilidade Parcial (ICP)

\begin{tabular}{|c|c|c|c|c|c|c|c|c|c|c|c|c|}
\hline \multirow{3}{*}{ Ajustes } & \multicolumn{4}{|c|}{2001 a 2006} & \multicolumn{4}{|c|}{2003 a 2006} & \multicolumn{4}{|c|}{2001 a 2002} \\
\hline & \multicolumn{2}{|c|}{ Ocorrência } & \multicolumn{2}{|c|}{ Índice } & \multicolumn{2}{|c|}{ Ocorrência } & \multicolumn{2}{|c|}{ Índice } & \multicolumn{2}{|c|}{ Ocorrência } & \multicolumn{2}{|c|}{ Índice } \\
\hline & $\mathrm{N}^{\circ}$ & $\%$ & Média & Mediana & $\mathrm{N}^{\circ}$ & $\%$ & Média & Mediana & $\mathrm{N}^{\mathrm{o}}$ & $\%$ & Média & Mediana \\
\hline $\begin{array}{l}\text { Ajustes de diferenças de critério de } \\
\text { hiperinflação (correção monetária do ativo } \\
\text { permanente de } 96 \text { e 97) }\end{array}$ & 77 & $91 \%$ & 1,39 & 1,04 & 53 & $91 \%$ & 1,15 & 1,02 & 24 & $89 \%$ & 1,92 & 1,11 \\
\hline Capitalização de juros (e amortização) & 75 & $88 \%$ & 0,96 & 0,98 & 51 & $88 \%$ & 0,97 & 0,99 & 24 & $89 \%$ & 0,94 & 0,98 \\
\hline $\begin{array}{l}\text { Planos de Pensão e outros benefícios de } \\
\text { aposentadoria }\end{array}$ & 67 & $79 \%$ & 1,16 & 1,00 & 46 & $79 \%$ & 0,97 & 0,99 & 21 & $78 \%$ & 1,58 & 1,00 \\
\hline $\begin{array}{l}\text { Diferimento de despesas (capitalização de } \\
\text { P\&D e outros) }\end{array}$ & 74 & $87 \%$ & 1,19 & 1,00 & 52 & $90 \%$ & 1,00 & 0,99 & 22 & $81 \%$ & 1,63 & 1,03 \\
\hline $\begin{array}{l}\text { Combinação de Negócios: ajustes do ágio } \\
\text { (e amortização) }\end{array}$ & 75 & $88 \%$ & 0,91 & 0,97 & 55 & $95 \%$ & 0,88 & 0,97 & 20 & $74 \%$ & 1,01 & 0,98 \\
\hline s. aiuste de col & 65 & $76 \%$ & 1,01 & 1,00 & 48 & $83 \%$ & 1,02 & 1,00 & 17 & $63 \%$ & 0,98 & 1,00 \\
\hline $\begin{array}{l}\text { Stock Options e outros planos de } \\
\text { recompensa }\end{array}$ & 15 & $18 \%$ & 1,04 & 1,01 & 13 & $22 \%$ & 1,04 & 1,01 & 2 & $7 \%$ & 1,01 & 1,01 \\
\hline Leasing financeiro & 32 & $38 \%$ & 0,99 & 1,00 & 27 & $47 \%$ & 0,98 & 1,00 & 5 & $19 \%$ & 1,08 & $\overline{1,00}$ \\
\hline $\begin{array}{l}\text { Instrumentos financeiros, inclusive } \\
\text { derivativos }\end{array}$ & 67 & $79 \%$ & 0,83 & 1,00 & 49 & $84 \%$ & 0,79 & 1,00 & 18 & $67 \%$ & 0,93 & 1,05 \\
\hline Incentivos fiscais & 25 & $29 \%$ & 0,96 & 0,98 & 16 & $28 \%$ & 0,94 & 0,95 & 9 & $33 \%$ & $\overline{0,99}$ & $\overline{1,00}$ \\
\hline Reconhecim & 32 & $38 \%$ & 0,96 & 1,00 & 21 & $36 \%$ & 0,92 & 0,99 & 11 & $41 \%$ & 1,05 & 1,03 \\
\hline Gastos com oferta púl & 8 & $9 \%$ & 0,95 & 0,97 & $\overline{7}$ & $12 \%$ & 0,95 & $\overline{0,96}$ & 1 & $4 \%$ & $\overline{0,98}$ & 0,98 \\
\hline Imposto de renda diferido rela & 85 & $100 \%$ & 0,91 & 0,99 & 58 & $100 \%$ & 1,03 & 1,00 & 26 & $96 \%$ & 0,62 & 0,95 \\
\hline Reavaliação de ativos (e depreciação) & 22 & $26 \%$ & 0,60 & 0,98 & 17 & $29 \%$ & 1,05 & 0,99 & 6 & $22 \%$ & $-0,66$ & 0,92 \\
\hline Outros & 71 & $84 \%$ & 1,00 & 0,99 & 51 & $88 \%$ & 1,11 & 1,00 & 20 & $74 \%$ & 0,70 & 0,98 \\
\hline Somatório dos Ajustes & 85 & & 1,17 & 0,96 & 58 & & $\mathbf{0 , 9 0}$ & $\mathbf{0 , 9 0}$ & 27 & & $\mathbf{1 , 7 9}$ & 1,09 \\
\hline
\end{tabular}

A Tabela 6 elenca o Índice de Comparabilidade Parcial (ICP) de cada categoria de ajuste efetuado ao lucro conforme as normas brasileiras (BRGAAP) para se obter o lucro conforme os USGAAP, para as 15 empresas analisadas. São apresentadas a frequência de cada ajuste, bem como a média e mediana de seu respectivo ICP.

$\mathrm{Na}$ mesma Tabela, algumas categorias de ajuste implicam um lucro menor segundo os BRGAAP, como, Reavaliação de Ativos, Instrumentos Financeiros e Combinação de Negócios, confirmando a teoria do conservadorismo do sistema contábil brasileiro, conforme preconizado por Gray e em parte corroborado por Santos et al. (2007), bem como na Tabela 2 para o período 2003-2006. Outras categorias, entretanto, geram efeito contrário à teoria, produzindo lucros maiores conforme os BRGAAP, como é o caso da Correção Monetária de 1996/97, do Diferimento de Despesas e dos critérios de contabilização dos Planos de Pensão e outros benefícios. Essa diversidade de impactos dos ajustes indica que o $p$-value de 63,94\% para o período de 2001-2006, conforme a Tabela 3, não se deve a que os lucros em BRGAAP e USGAAP sejam estatisticamente semelhantes, mas sim que há uma grande concentração de números em polos opostos.

Observa-se que essas categorias de ajustes apresentam ICPs expressivamente superiores a 1 justamente nos primeiros dois anos da série, decrescendo posteriormente. Isso explicaria porque o sistema contábil brasileiro caracterizou-se como menos 
conservador que o americano nesse período, conforme questão levantada em Santos et al. (2007).

A Tabela 7 introduz na lista de ajustes constantes da Tabela 6, um número de ordem segundo a relevância do impacto, bem como a frequência de cada ajuste. A ordem de relevância do impacto é dada pela média do ICP da categoria.

Pela tabela, os dois ajustes que se destacam em relevância apresentam impactos contrários no lucro: a Correção Monetária (ICP de 1,39), que tornaria o lucro $39 \%$ maior pelas normas brasileiras em comparação com as normas americanas (menor conservadorismo), e a Reavaliação de Ativos (ICP de 0,60), que tornaria o lucro $40 \%$ menor segundo os BRGAAP em comparação com os USGAAP (maior conservadorismo).

Dentre os itens que ocorrem com maior frequência no período total 2001-2006, além do Imposto de Renda $(100 \%$, com ICP de 0,90$)$, estão Correção Monetária $(91 \%, 1,39)$, Juros $(88 \%, 0,96)$, Combinação de Negócios $(88 \%, 0,91)$ e Diferimentos de Despesas $(87 / \%$, $1,19)$. Isso significa que, por exemplo, a Correção Monetária é apontada em $91 \%$ das empresas que publicaram a Tabela de Conciliação do Lucro dos BRGAAP para os USGAAP, e tornaria o lucro das empresas que o apontaram, em média $39 \%$ superior pelos BRGAAP em relação ao lucro apurado conforme os USGAAP.

Tabela 7 - Ajustes nos Lucros: Impacto no Lucro e Frequência de Ocorrência

\begin{tabular}{l|c|c|c|c}
\hline \multirow{2}{*}{\multicolumn{1}{c|}{ Ajustes }} & \multicolumn{2}{c}{2001 a 2006 } \\
\cline { 2 - 4 } & \multicolumn{2}{c|}{ Impacto } & \multicolumn{2}{c}{ Ocorrências } \\
\cline { 2 - 4 } & Média & Ordem & \multicolumn{1}{c}{$\%$} & Ordem \\
\hline $\begin{array}{l}\text { Ajustes de diferenças de critério de hiperinflação (correção } \\
\text { monetária do ativo permanente de 96 e 97) }\end{array}$ & 1,39 & 1 & $92 \%$ & 2 \\
\hline Diferimento de despesas (capitalização de P\&D e outros) & 1,19 & 3 & $88 \%$ & 4 \\
\hline Planos de Pensão e outros benefícios de aposentadoria & 1,16 & 5 & $80 \%$ & 6 \\
\hline Stock Options e outros planos de recompensa & 1,04 & 9 & $18 \%$ & 7 \\
\hline Investimentos: ajuste de consolidação & 1,01 & 11 & $77 \%$ & 7 \\
\hline Outros & 1,00 & 11 & $85 \%$ & 5 \\
\hline Leasing financeiro & 0,99 & 11 & $38 \%$ & 8 \\
\hline Reconhecimento da receita & 0,96 & 9 & $38 \%$ & 8 \\
\hline Capitalização de juros (e amortização) & 0,96 & 9 & $89 \%$ & 3 \\
\hline Incentivos fiscais & 0,96 & 9 & $30 \%$ & 9 \\
\hline Gastos com oferta pública de ações & 0,95 & 8 & $10 \%$ & 11 \\
\hline Combinação de Negócios: ajustes do ágio (e amortização) & 0,91 & 7 & $89 \%$ & 3 \\
\hline Imposto de renda diferido relativo aos ajustes & 0,91 & 6 & $100 \%$ & 1 \\
\hline Instrumentos financeiros, inclusive derivativos & 0,83 & 4 & $80 \%$ & 6 \\
\hline Reavaliação de ativos (e depreciação) & 0,60 & 2 & $26 \%$ & 10 \\
\hline
\end{tabular}

A Tabela 8 analisa a consistência do impacto dos ajustes ao lucro ao longo do tempo, uma vez que um mesmo ajuste pode contribuir ora para aumentá-lo ora para diminuí-lo (ICP maior ou menor que 1). Assim, por exemplo, a Correção Monetária em todas as vezes que ocorre $(77=100 \%)$ teve ICP positivo, gerando lucro pelos BRGAAP superiores aos lucros pelos USGAAP. Já os Incentivos Fiscais geraram lucro pelos BRGAAP sempre menores que os gerados segundo os USGAAP. Mas a maioria dos ajustes da Tabela 8 impacta o lucro ora positiva ora negativamente ao longo do período. Por exemplo, a categoria Leasing Financeiro em 57\% das ocorrências gera lucro menor em BRGAAP e em $43 \%$ das ocorrências gera lucro maior. 
Tabela 8 - Consistência dos Ajustes no Tempo

\begin{tabular}{|l|c|c|c|c|c}
\hline \multirow{2}{*}{\multicolumn{1}{c|}{ Ajustes }} & \multicolumn{2}{c|}{$\begin{array}{c}\text { Gera lucro BR } \\
\text { GAAP Menor }\end{array}$} & \multicolumn{2}{c|}{$\begin{array}{c}\text { Gera lucro BR } \\
\text { GAAP Maior }\end{array}$} & \multirow{2}{*}{ Total } \\
\cline { 2 - 5 } & \multicolumn{2}{|c|}{ ICP<1 } & \multicolumn{2}{c|}{ ICP>1 } & \\
\cline { 2 - 5 } & Quant. & $\%$ & Quant. & $\%$ & \\
\hline $\begin{array}{l}\text { Ajustes de diferenças de critérios de hiperinflação } \\
\text { (Correção monetária do ativo permanente de 96 e 97) }\end{array}$ & 0 & $0 \%$ & 77 & $100 \%$ & 77 \\
\hline Juros Capitalizados (e amortização) & 47 & $63 \%$ & 28 & $37 \%$ & 75 \\
\hline Plano de Pensão e Outros benefícios & 42 & $63 \%$ & 25 & $37 \%$ & 67 \\
\hline $\begin{array}{l}\text { Diferimento de despesas (capitalização de custos e } \\
\text { despesas, P\&D) }\end{array}$ & 39 & $53 \%$ & 35 & $47 \%$ & 74 \\
\hline $\begin{array}{l}\text { Combinação de Negócios: Ajustes, ágio na aquisição } \\
\text { empresas }\end{array}$ & 56 & $75 \%$ & 19 & $25 \%$ & 75 \\
\hline Investimentos: Ajuste de consolidação & 28 & $43 \%$ & 37 & $57 \%$ & 65 \\
\hline Stock Options e Outros planos de recompensa & 2 & $13 \%$ & 13 & $87 \%$ & 15 \\
\hline Leasing financeiro & 16 & $50 \%$ & 16 & $50 \%$ & 32 \\
\hline $\begin{array}{l}\text { Derivativos e Titulos: Ajuste contábeis de } \\
\text { instrumentos financeiros e derivativos. }\end{array}$ & 32 & $48 \%$ & 35 & $52 \%$ & 67 \\
\hline Incentivos Fiscais & 21 & $84 \%$ & 4 & $16 \%$ & 25 \\
\hline Reconhecimento de receita & 15 & $47 \%$ & 17 & $53 \%$ & 32 \\
\hline Gastos com oferta pública de ações & 8 & $100 \%$ & 0 & $0 \%$ & 8 \\
\hline Impostos diferido relativo aos ajustes & 47 & $55 \%$ & 38 & $45 \%$ & 85 \\
\hline Ajuste de reavaliação de ativos (depreciação) & 21 & $91 \%$ & 2 & $9 \%$ & 23 \\
\hline Outros & 46 & $65 \%$ & 25 & $35 \%$ & 71 \\
\hline
\end{tabular}

\subsection{ANÁLISE DO IMPACTO (ICP) DOS AJUSTES MAIS SIGNIFICATIVOS}

Tabela 9 - Análise do ICP: Ajuste da Correção Monetária 1996/97

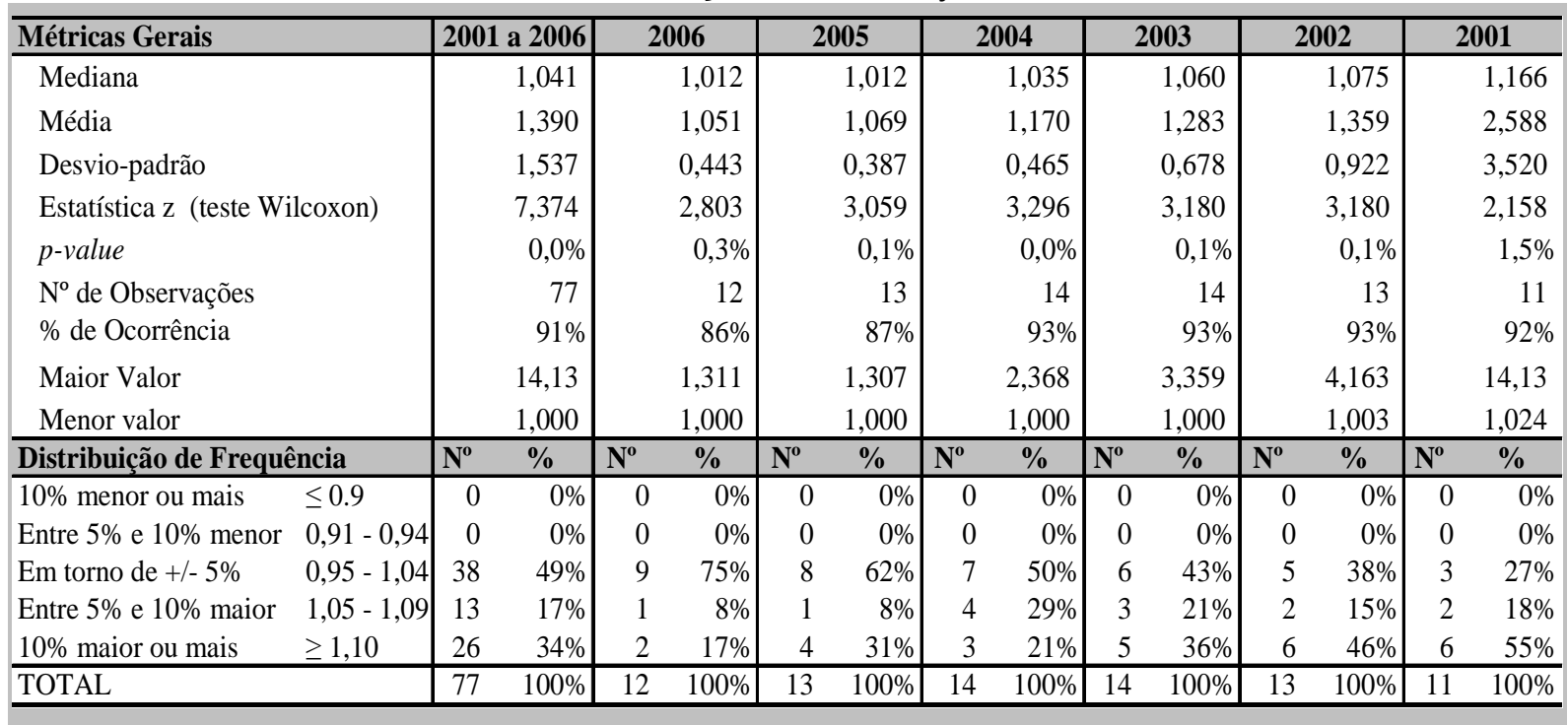


Conforme a Tabela 9, a Correção Monetária é uma categoria de ajuste que contribui consistentemente para um lucro maior segundo os BRGAAP em relação aos USGAAP em todo o período analisado, contrariamente à previsão teórica do conservadorismo das práticas contábeis brasileiras. Assim, o ICP dessa categoria é sempre maior que 1, tanto pela média quanto pela mediana, e estatisticamente significativo em todos os anos, ocorrendo em pelo menos $86 \%$ das empresas, em todo o período. É expressiva a concentração das ocorrências na faixa de ICPs maiores que 1,10, ou seja, com grande freqüência, a Correção Monetária contribui para gerar lucros apurados pelos BRGAAP significativamente maiores que pelos USGAAP. É de notar que o impacto dessa categoria de ajuste é bastante expressivo no início do período estudado (subperíodo 2001-2002), decrescendo com o tempo. Isso reflete o impacto da extinção da correção monetária no Brasil a partir de 1995 (por interveniência da autoridade tributária sobre a contabilidade financeira, mediante a Lei do Imposto de Renda daquele ano - em postura institucional típica dos países latinos). Entretanto, pelos padrões internacionais, a economia brasileira foi considerada hiperinflacionária até 1996/97 (inflação acumulada de 100\% ou mais nos últimos 3 anos).

Assim, por um lado, a harmonização internacional levaria as empresas brasileiras a corrigir o Ativo Permanente existente em 1996/97 pela inflação acumulada no período. Isso geraria, num primeiro momento, um grande aumento no valor do Ativo Permanente, com o correspondente aumento no Patrimônio Líquido. Por outro lado, grande parte desse aumento terá sido diluída pelas depreciações a maior a lançar retroativamente para o período de 1996 a 2007, restando apenas o impacto (negativo no resultado a partir de 2008) da depreciação a maior dos ativos com vida útil superior a 10 anos e ainda não totalmente depreciados. Dada essa diluição dos efeitos deste ajuste no tempo, seu impacto não deverá mostrar-se tão expressivo na adoção do padrão internacional no Brasil.

Como mostra a Tabela 10, o ajuste decorrente das diferenças de tratamento do Ágio na Combinação de Negócios gera resultados, em média, menores no Brasil em todos os anos analisados. Isso se deverá ao fato de que, por um lado, o ágio no Brasil é maior (diferença entre valor pago e valor contábil dos ativos) do que nos EUA (diferença entre o valor pago e o valor de mercado dos ativos); por outro, ao contrário dos EUA, o ágio no Brasil é amortizável, inclusive para efeitos do Imposto de Renda. Isso tem levado, conforme percepção do mercado, a possíveis exageros tanto na frequência de operações de combinações de negócios como no valor do ágio (goodwill) praticado nessas operações. Com efeito, várias empresas, têm reconhecido em suas demonstrações financeiras (mediante baixa imediata do ágio como perda) que o único benefício futuro a ser gerado pela operação seria a vantagem tributária proporcionada pela amortização do ágio.

As expressivas diferenças, tanto no montante quanto na distribuição de freqüência dos resultados, inclusive com oscilação entre extremos, indica elevada inconsistência e aleatoriedade na análise do impacto desse ajuste ao longo do período. Com efeito, observam-se concentrações de ocorrências tanto de pequenos (indicando possíveis amortizações graduais) como de grandes impactos (indicando possíveis baixas imediatas), quer gerando lucros maiores, quer menores segundo os BRGAAP em relação aos USGAAP. 
Tabela 10 - Análise do ICP: Ajuste de Ágio na Combinação de Negócios

\begin{tabular}{|c|c|c|c|c|c|c|c|c|c|c|c|c|c|c|}
\hline \multicolumn{2}{|l|}{ Métricas Gerais } & 2001 a 2006 & \multicolumn{2}{|c|}{2006} & \multicolumn{2}{|c|}{2005} & \multicolumn{2}{|c|}{2004} & \multicolumn{2}{|c|}{2003} & \multicolumn{2}{|c|}{2002} & \multicolumn{2}{|c|}{2001} \\
\hline Mediana & & 0,969 & & 0,983 & & 0,972 & & 0,977 & & 0,945 & & 0,955 & & 0,993 \\
\hline Média & & 0,912 & & 0,790 & & 0,921 & & 0,908 & & 0,883 & & 0,889 & & 1,233 \\
\hline Desvio-padrão & & 0,619 & & 0,806 & & 0,470 & & 0,322 & & 0,547 & & 0,702 & & 0,775 \\
\hline Estatística z (teste Wi & lcoxon) & $-2,731$ & & $-0,943$ & & - 1,647 & & $-1,726$ & & 2,229 & & 0,943 & & 0,169 \\
\hline$p$-value & & $0,3 \%$ & & $17,3 \%$ & & $5,0 \%$ & & $4,2 \%$ & & $1,3 \%$ & & $17,3 \%$ & & $56,7 \%$ \\
\hline $\mathrm{N}^{\mathrm{o}}$ de Observações & & 75 & & 13 & & 14 & & 14 & & 14 & & 13 & & 7 \\
\hline$\%$ de Ocorrência & & $88 \%$ & & $93 \%$ & & $93 \%$ & & $93 \%$ & & $93 \%$ & & $93 \%$ & & $58 \%$ \\
\hline Maior Valor & & 2,748 & & 2,027 & & 2,027 & & 1,258 & & 2,213 & & 2,303 & & 2,748 \\
\hline Menor valor & & $-1,046$ & & $-1,0458$ & & 0,154 & & 0,507 & & 0,223 & & 0,912 & & 0,839 \\
\hline Distribuição de Freque & ncia & $\mathrm{N}^{\mathbf{0}}$ & $\mathrm{N}^{0}$ & $\%$ & $\mathbf{N}^{\mathbf{o}}$ & $\%$ & $\mathrm{~N}^{\mathbf{o}}$ & $\%$ & $\mathbf{N}^{0}$ & $\%$ & $\mathrm{~N}^{\mathbf{o}}$ & $\%$ & $\mathbf{N}^{\mathbf{0}}$ & $\%$ \\
\hline $10 \%$ menor ou mais & $\leq 0.9$ & $28 \%$ & 3 & $23 \%$ & 4 & $29 \%$ & 4 & $29 \%$ & 5 & $36 \%$ & 4 & $31 \%$ & 1 & $14 \%$ \\
\hline Entre $5 \%$ e $10 \%$ menor & $0,91-0,94$ & $9 \%$ & 1 & $8 \%$ & 1 & $7 \%$ & 1 & $7 \%$ & 2 & $14 \%$ & 1 & $8 \%$ & 1 & $14 \%$ \\
\hline Em torno de $+/-5 \%$ & $0,95-1,04$ & $41 \%$ & 6 & $46 \%$ & 6 & $43 \%$ & r & $50 \%$ & 6 & $43 \%$ & 4 & $31 \%$ & 2 & $29 \%$ \\
\hline Entre $5 \%$ e $10 \%$ maior & $1,05-1,09$ & $5 \%$ & 0 & $0 \%$ & 2 & $14 \%$ & , & $0 \%$ & 0 & $0 \%$ & 1 & $8 \%$ & 1 & $14 \%$ \\
\hline $10 \%$ maior ou mais & $\geq 1,10$ & $16 \%$ & 3 & $23 \%$ & 1 & $7 \%$ & 2 & $14 \%$ & 1 & $7 \%$ & 3 & $23 \%$ & 2 & $29 \%$ \\
\hline TOTAL & & $100 \%$ & 13 & $100 \%$ & 14 & $100 \%$ & 14 & $100 \%$ & 14 & $100 \%$ & 13 & $100 \%$ & 7 & $100 \%$ \\
\hline
\end{tabular}

Tabela 11 - Análise do ICP: Instrumentos Financeiros, inclusive Derivativos

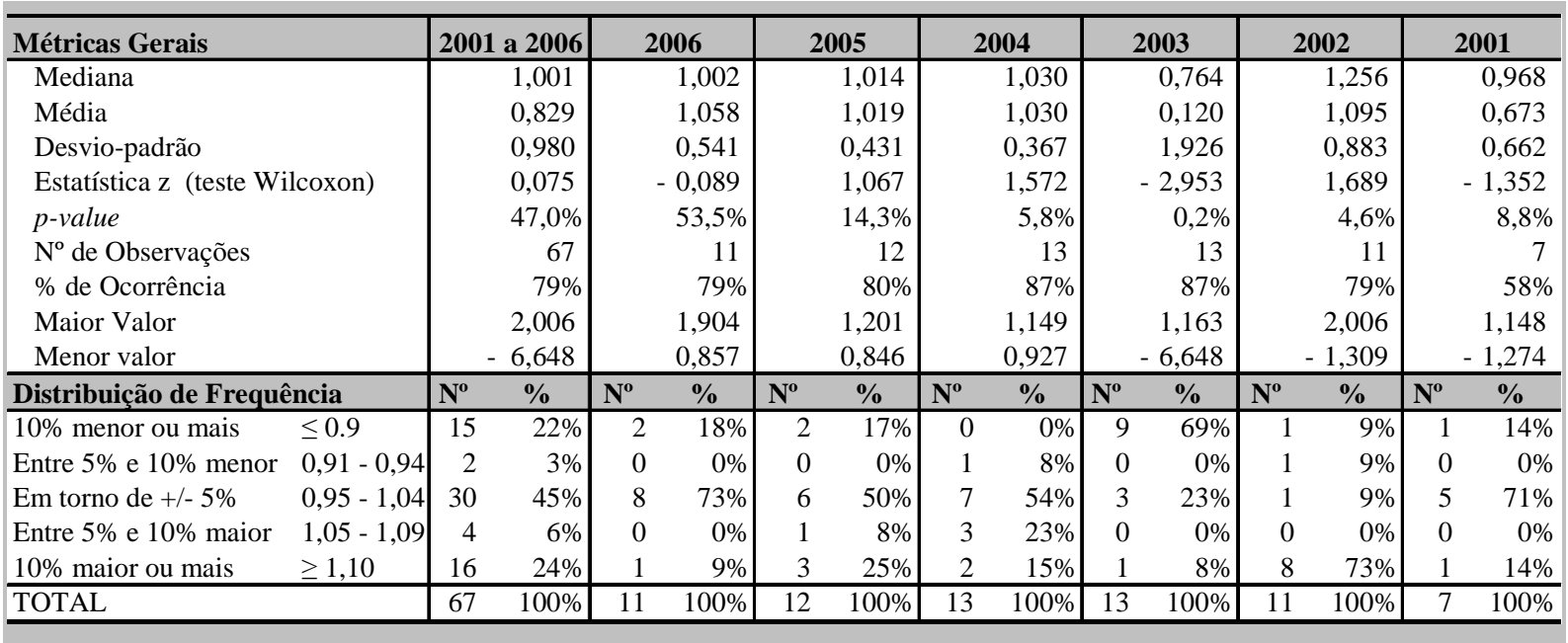

A Tabela 11 apresenta os números dos ICPs da categoria Instrumentos Financeiros e Derivativos, os quais mostram grandes oscilações, tanto na média quanto na distribuição de freqüência de seus impactos no lucro das empresas. Assim, no período total 2001-2006, em $22 \%$ das ocorrências o ICP indica um lucro pelo menos $10 \%$ menor, mas $24 \%$ das ocorrências gerariam um lucro pelo menos 10\% maior. Comparando 2001 (73\% das ocorrências gerando um lucro pelo menos 10\% maior) com 2002 (69\% das ocorrências gerando lucro pelo menos $10 \%$ menor), tem-se melhor visão da amplitude dessa inconsistência. Essas oscilações das diferenças se devem, certamente, a que a volatilidade do valor de mercado, inerente a esses instrumentos financeiros, é reconhecida nos EUA (marked to market), enquanto que no Brasil esses instrumentos financeiros são mantidos pelo seu valor histórico. Grande parte dos derivativos estava, inclusive, fora do balanço das empresas. Essas diferenças serão ora superadas com a adoção do padrão internacional. 
Tabela 12 - Análise do ICP: Reavaliação de Ativos (depreciação)

\begin{tabular}{|c|c|c|c|c|c|c|c|c|}
\hline Métricas Gerais & 2001 a 2006 & 2006 & 2005 & 2004 & 2003 & 2002 & & 001 \\
\hline Mediana & 0,982 & 0,995 & 0,991 & 0,978 & 0,981 & 0,887 & & 0,959 \\
\hline Média & 0,603 & 1,130 & 1,139 & 0,925 & 0,919 & 0,298 & & 1,610 \\
\hline Desvio-padrão & 0,878 & 0,591 & 0,594 & 0,427 & 0,383 & 0,428 & & 1,821 \\
\hline Estatística z (teste Wilcoxon) & $-2,776$ & $-2,556$ & $-0,674$ & $-1,826$ & $-1,604$ & $-1,604$ & & 1,604 \\
\hline$p$-value & $0,3 \%$ & $0,5 \%$ & $25,0 \%$ & $3,4 \%$ & $5,4 \%$ & $5,4 \%$ & & $5,4 \%$ \\
\hline $\mathrm{N}^{\circ}$ de Observações & 23 & 5 & 5 & 4 & 3 & 3 & & 3 \\
\hline \% de Ocorrência & $27 \%$ & $36 \%$ & $33 \%$ & $27 \%$ & $20 \%$ & $21 \%$ & & $25 \%$ \\
\hline Maior Valor & 1,834 & 1,834 & 1,834 & 0,993 & 0,983 & 0,961 & & 0,998 \\
\hline Menor valor & $-6,788$ & 0,836 & 0,887 & 0,750 & 0,791 & $-0,953$ & & 6,788 \\
\hline Distribuição de Frequência & $\mathbf{N}^{\mathbf{0}}$ & $\mathbf{N}^{\mathbf{o}}$ & $\mathbf{N}^{\mathbf{0}}$ & $\mathbf{N}^{\mathbf{o}}$ & $\mathbf{N}^{\mathbf{0}}$ & $\mathbf{N}^{\mathbf{0}}$ & $\mathbf{N}^{\mathbf{o}}$ & $\%$ \\
\hline $10 \%$ menor ou mais & $30 \%$ & $20 \%$ & $20 \%$ & $25 \%$ & $33 \%$ & $67 \%$ & 1 & $33 \%$ \\
\hline Entre $5 \%$ e $10 \%$ menor $0,91-0,94$ & $0 \%$ & $0 \%$ & $0 \%$ & $0 \%$ & $0 \%$ & $0 \%$ & 0 & $0 \%$ \\
\hline Em torno de $+/-5 \%$ & $61 \%$ & $60 \%$ & $60 \%$ & $75 \%$ & $67 \%$ & $33 \%$ & 2 & $67 \%$ \\
\hline Entre $5 \%$ e $10 \%$ maior $1,05-1,09$ & $0 \%$ & $0 \%$ & $0 \%$ & $0 \%$ & $0 \%$ & $0 \%$ & 0 & $0 \%$ \\
\hline $10 \%$ maior ou mais & $9 \%$ & $20 \%$ & $20 \%$ & $0 \%$ & $0 \%$ & $0 \%$ & 0 & $0 \%$ \\
\hline TOTAL & $100 \%$ & $100 \%$ & $100 \%$ & $100 \%$ & $100 \%$ & $100 \%$ & 3 & $100 \%$ \\
\hline
\end{tabular}

Na Tabela 12, o ajuste devido à depreciação a maior resultante da Reavaliação do Ativo Imobilizado é pouco apontado (ocorrência em torno de $20 \%$ a $36 \%$ ) pelas empresas. Isso se deverá às restrições há anos colocadas pela CVM no intuito de coibir exageros na utilização desse instrumento, determinando que as empresas definam antecipadamente políticas consistentes em relação aos ativos a serem reavaliados e com que frequiência.

De fato, nos períodos de alta inflação no Brasil, a reavaliação do imobilizado era praticada como antídoto à sua defasagem de valor, diante da aplicação de índices de correção monetária pouco realistas, definidos pelo governo como instrumento de política monetária. Entretanto, essa prática tem gerado abusos, provocando não raro reavaliações infladas, que teriam motivado as citadas restrições da CVM e, agora, com a Nova Lei das S/As, à supressão da reavaliação - apesar de ser prática permitida pelo IFRS, mas não pelos USGAAP.

No entanto, como mostra a Tabela 12, quando a Reavaliação do Imobilizado ocorre nas empresas analisadas, o seu impacto é significativo, contribuindo em média para uma redução do lucro em BRGAAP em relação aos USGAAP em torno de 40\%, no período 2001 2006. Essa categoria de ajuste se mostra consistente ao longo do tempo e entre empresas, ao contribuir quase sempre para a geração de resultados menores no Brasil, confirmando a teoria do conservadorismo das práticas contábeis brasileiras.

É de notar, contudo, que no universo das S/As fechadas e demais empresas de grande porte, todas doravante obrigadas à contabilização pelas normas internacionais, e que não se encontravam sob a regulação da CVM, a prática da Reavaliação do Ativo Imobilizado tem sido freqüente e muito relevante. (Ver, por exemplo, Niero \& Valente, 2008). 


\section{CONCLUSÃO}

Aprofundando estudos anteriores sobre as diferenças de lucro apurados conic: me as normas brasileiras (BRGAAP) e americanas (USGAAP), o presente trabalho aplicou o Índice de Conservadorismo (IC) de Gray (1980) ao lucro e, em particular, o Índice de Comparabilidade Parcial (ICP) de Weetman et al. (1998) aos ajustes ao lucro publicados pelas emissoras brasileiras de ADRs na NYSE, no período 2001-2006.

A verificação de um IC mediano de 0,91 , estatisticamente significativo a $1 \%$, para o período 2003-2006 (após desconsideração do subperíodo 2001-2002, impactado por ajustes heterodoxos da Correção Monetária), não apenas confirmaria a previsão teórica do conservadorismo da contabilidade brasileira, dentro da tradição latina e euro-continental, como permitiria, ainda, estimar um novo patamar de lucro, aproximadamente 9,5\% superior ao atual, a ser ensejado pela presente transição para o padrão internacional.

Mediante cálculo dos ICPs, foi possível identificar a relevância do impacto de cada categoria de ajuste ao resultado, a frequência com que esse ajuste ocorreu, e a consistência do impacto desse ajuste entre empresas e ao longo do tempo.

Assim, verificou-se que algumas categorias de ajuste implicam um lucro menor conforme os BRGAAP, confirmando a teoria; outros ajustes, entretanto, geram efeito contrário à teoria produzindo lucros maiores em BRGAAP. Observou-se, ainda, que várias categorias de ajustes apresentam um ICP expressivamente superior a 1 justamente nos primeiros dois anos da série, decrescendo posteriormente, o que explicaria a inconsistência da mediana do IC no tempo (maior que 1 nos dois primeiros anos e menor que 1 nos anos seguintes), identificada por Santos, et al. (2007). Em ambos os casos, a Correção Monetária de 1996/97 mostrou-se como o grande impactante, além dos Planos de Pensão e do Diferimento de Despesas. Essa diversidade de impactos dos ajustes explica a concentração de números em polos opostos da distribuição de frequência. Desse modo, entre os ajustes mais relevantes e apontados com maior frequência pelas empresas no período figuram a Correção Monetária $(91 \%, I C P=1,39)$, Reavaliação de Ativos $(26 \%$, $I C P=0,6)$, Diferimentos de Despesas $(87 / \%$, ICP $=1,19)$; Instrumentos Financeiros $(79 \%$, ICP $=0,83)$, Planos de Pensão e outros benefícios $(79 / \%$, ICP $=1,16)$ e Combinação de Negócios $(88 \%$, ICP=0,91).

Entre as limitações do presente trabalho destacam-se duas principais, decorrentes da indisponibilidade de dados mais precisos para o tratamento das questões levantadas. Por um lado, a utilização das séries históricas dos USGAAP não se configura como proxy perfeita dos IFRS, deixando de abordar algumas diferenças de enfoques e contextualização dos dois sistemas. Além disso, não são aleatórias as amostras das 30 empresas brasileiras emissoras de ADRs na NYSE e, em particular, das 15 empresas que publicaram a Tabela de Reconciliação do Lucro no Formulário $20-\mathrm{F}$, o que limita a extensão dos resultados ao universo das empresas brasileiras sujeitas à adoção do padrão internacional.

Este estudo, ao procurar identificar os impactos das diferenças entre as normas brasileira e americana no resultado das emissoras de ADRs na NYSE, poderá talvez contribuir para identificar maiores urgências na regulamentação de determinados tópicos no processo de migração para o IFRS, minorando custos de adaptação, com incremento da transparência em benefício dos usuários da informação contábil. 


\section{REFERÊNCIAS}

BARTH, M.; CLINCH, G. International accounting differences and their relation to share prices: evidence from U.K., Australian and Canadian firms. Contemporary Accounting Research. Vol 13, n. 1, p. 134-170, Spring 1996.

BLACK, E. L.; WHITE, J. J. An international comparison of income statement and balance sheet information: Germany, Japan and US. European Accounting Review. Vol.12, n.1, p. 29-46, may 2003.

BRASIL. Nova Lei das S/As. Lei 11.638 de 28 dez. 2007. Altera e revoga dispositivos da Lei n 6.404, de 15 de dezembro de 1976, e da Lei no 6.385, de 7 de dezembro de 1976, e estende às sociedades de grande porte disposições relativas à elaboração e divulgação de demonstrações financeiras. Disponível em <<http://www.planalto.gov.br/ccivil_03/_ato2007-2010/2007/Lei/L11638 >>.

CARVALHO, L. F. et al. Principais diferenças entre BR GAAP e os US GAAP. In: SEMEAD, X, 2007, São Paulo. Anais do X SEMEAD, São Paulo: USP, 2007, p. 1-14.

CHANCHANI, S.; WILLETT, R. An empirical assessment of Gray's accounting value constructs. The International Journal of Accounting. Urbana, vol. 39, n. 2, p. 125-154, 2004.

CHOI, F.; MEEK, G. K. International accounting. $5^{\text {th }}$ ed. Upper Saddle River: Pearson, 2005.

CHOI, F. D. S. et al. Analyzing foreign financial statements: The use and misuse of international ratio analysis. Journal of International Business Studies (pre-1986). Atlanta, vol. 14, n. 1. Spring/Summer 1983.

COOKE, T. E. The impact of accounting principles on profits: the US versus Japan. Accounting and Business Research. Vol 23, n. 92, p. 460-476, Autumn1993.

COSTA, A.C.O. Conservadorismo e os países da América do Sul: um estudo da aplicação do conservadorismo em cinco países da América do Sul. 2004. 94f. Dissertação (Mestrado em Ciências Contábeis). Fundação Instituto Capixaba de Pesquisas em Contabilidade, Economia e Finanças, Vitória.

COTIAS, A. Investidor pune mercados sem norma internacional. Valor Econômico, 26 jun 2006. 
DOUPNIK, T. S; , TSAKUMIS, G.Y. A . A critical review of tests of Gray's theory of cultural relevance and suggestions for future research. Journal of Accounting Literature. Gainesville, vol. 23, p. 1-48. 2004.

EPSTEIN, B. J. et al. GAAP 2007: Interpretation and application of generally accepted accounting principles. Somerset: Wiley, 2006.

GRAY, S. J. Cultural influences and the international classification of accounting systems. Paper presented at the European Institute for Advanced Studies in Management Workshop on Accounting and Culture: Amsterdan, june, 1985.

GRAY, S. J. The impact of international accounting differences from a security analysis perspective: some European evidence. Journal of Accounting Research (Spring): 64-76, 1980.

GRAY, S. J. Towards a theory of cultural influence on the development of accounting systems internationally. Abacus. Sidney, vol. 24, n.1, p. 1-15. Mar 1988.

HENDRIKSEN, E. S.;VAN BREDA, M. F. Accounting theory. 5 ed. Irwin, 1992.

HOFSTEDE, G. H. Culture's consequences : international differences in work-related values. Beverly Hills, Calif. : Sage Publications, 1980.

IUDÍCIBUS, S. de. Teoria da contabilidade. 5a ed. São Paulo: Atlas, 1997.

KPMG. Comparações entre práticas contábeis. KPMG, 2001. Disponível em: <<http://www.kpmg.com.br/publicacoes_livros_tecnicos.asp?ft=3\&ffx=3>>. Acesso em 26/04/06.

LEMES, S. et al. Comparabilidade entre os BR GAAP e os US GAAP: algumas evidências das companhias brasileiras listadas na NYSE. In: ENANPAD, XXXI, 2007, Rio de Janeiro. Anais do XXXI ENANPAD. Rio de Janeiro: ANPAD, 2007, p 1-15.

NIERO, N.; VALENTE, G. Reavaliação criou reserva de R\$ 40 bi. Valor Econômico. 27 fev. 2008.

NIYAMA, J. K. Contabilidade internacional. São Paulo: Atlas, 2005.

NOBES, C.; PARKER, R. Comparative international accounting. 9 ed. London: Prentice Hall, 2006.

NORTON, J. The impact of financial accounting practices on the measurement of profit and equity: Australia versus United States. Abacus. Sidney, vol. 31, n.2, p.178-200, September 1995. 
NYSE - New York Stock Exchange. Disponível em <<http://www.nyse.com/about/listed/listed.html>>. Acesso em 31 dez. 2007.

PEREZ JUNIOR, J.H., Conversão de demonstrações contábeis, São Paulo: Atlas, 2005.

PRICEWATERHOUSECOOPERS. Semelhanças e diferenças: IFRS, USGAAP e práticas Contábeis adotadas no Brasil. PricewaterhouseCoopers, 2004. Disponível em: <<http://www.pwc.com.br>>. Acesso em 26/04/2006.

RADEBAUGH, L. H., GRAY, S. J., BLACK, E. L. International accounting and multinational enterprises. Hoboken -USA: Wiley, 2006.

SANTOS, E. S. Contribuição para integração da competitividade por inovação em instrumentos de controladoria: o resultado econômico competitivo de emissoras brasileiras de ADRs. 2004. 272f. Tese (Doutorado em Ciências Contábeis). Faculdade de Economia e Administração da Universidade de São Paulo, São Paulo. 2004.

SANTOS, E. S. et al. US GAAP x normas brasileiras: Há diferenças significativas no valor do lucro reportado pelas empresas brasileiras com ADRs na NYSE? In: ENANPAD, XXXI, 2007, Rio de Janeiro. Anais do XXXI ENANPAD. Rio de Janeiro: ANPAD, 2007, p 1-15.

SANTOS, L.S.R. Conservadorismo contábil e timeliness: evidências empíricas nos demonstrativos contábeis nas empresas brasileiras com ADRs negociados na bolsa de Nova Iorque. 2006 66f. Dissertação (Mestrado em Ciências Contábeis). Fundação Instituto Capixaba de Pesquisas em Contabilidade, Economia e Finanças, Vitória. 2006.

SAUDAGARAN, S. M. International Accounting: a user perspective. Mason (Ohio): Thomson, 2001.

WEETMAN, P. E. et al. Profit measurement and UK accounting standards: a case of increasing disharmony in relation to US GAAP and IASs. Accounting and Business Research. Kingston, v. 29, n. 3, p. 189-208. Summer 1998.

WEETMAN, P. E., \& GRAY, S. J. A comparative international analysis of the impact of accounting principals on profits: the USA versus the UK, Sweden and the Netherlands. Accounting and Business Research. Kingston, v. 21, n. 83, p. 363-379. Autumn 1991.

WEETMAN, P. E., \& GRAY, S. J. International financial analysis and comparative corporate performance: the impact of UK versus US accounting principles on earnings. Journal of International Financial Management and Accounting. v. 2, n. 2 e 3. Summer/Autumn1990.

WEFFORT, E. F. J. O Brasil e a Harmonização Contábil Internacional: Influências dos Sistemas Jurídico e Educacional, da Cultura e do Mercado. 2003. 295f. Tese (Doutorado 
em Ciências Contábeis), Faculdade de Economia e Administração da Universidade de São Paulo, São Paulo, 2003.

ZAMBON, Stefano. Increased Disharmony or Twin Accounting? A Closer Look at the Compatibility of UK Accounting Practices with US GAAP. Discussion Paper Series in Accounting, Finance and Banking, Department of Economics and ISMA Center, University of Reading, no. 57, may 1998. Acesso em: 30/04/2008. Disponível em: <<http://www.rdg.ac.uk/Econ/Econ/workingpapers/accdp57.pdf>>. 


\section{ENDEREÇO DOS AUTORES}

Escola de Administração

Fundação Getúlio Vargas

Av. 9 de Julho, 2029 - Bela Vista

São Paulo, SP - Brasil

01313-902

Faculdade de Economia Administração e Contabilidade

Universidade de São Paulo

Av.Prof. Lucianao Gualberto, 908 - Butantã

Sao Paulo, SP - Brasil

05508-900

${ }^{\mathrm{i}}$ Agradecimento a Gustavo Henrique Falciano, pelo apoio na coleta de dados. 